\title{
On the Performance of the Canadian Land Surface Scheme Driven by the ERA5 Reanalysis over the Canadian Boreal Forest
}

\author{
M. AlvES \\ Department of Civil and Water Engineering, Université Laval, Quebec, and Ouranos, Montreal, and CentrEau, \\ Université Laval, Quebec, Quebec, Canada \\ D. F. NADEAU \\ Department of Civil and Water Engineering, and CentrEau, Université Laval, Quebec, Quebec, Canada \\ B. MUSIC \\ Department of Civil and Water Engineering, Université Laval, Quebec, and Ouranos, Montreal, Quebec, Canada \\ F. ANCTIL AND A. PARAJUli \\ Department of Civil and Water Engineering, and CentrEau, Université Laval, Quebec, Quebec, Canada
}

(Manuscript received 8 August 2019, in final form 26 March 2020)

\begin{abstract}
The Canadian Land Surface Scheme (CLASS) has been applied over the years in coupled and uncoupled (offline) modes at local, regional, and global scales using various forcing datasets. In this study, CLASS is applied at a local scale in the offline configuration to evaluate its performance when driven by the ERA5 reanalysis. Simulated surface energy fluxes, as well as several other water balance components, are investigated at four sites across the Canadian boreal biome. The results from CLASS driven by ERA5 (CLASSRNL) are compared with available in situ measurements, as well as with results from CLASS driven by observations (CLASS-CTL). Additional simulations are conducted to evaluate the effects of biases in the ERA5 precipitation, where CLASS is forced by ERA5 data, but with ERA5 precipitation being replaced by observed precipitation (CLASS-RNL-ObsP). The results show that simulated surface variables in CLASS-RNL are in good agreement with observations as well as with those simulated in CLASS-CTL. The CLASS-RNL captures well the observed annual cycles of the surface energy and water fluxes, as well as the year-to-year variation of snow depth, soil temperature, and soil moisture. A strong correlation is found between the observed and CLASSRNL simulated snow depth and soil temperature. Biases in the ERA5 precipitation did not affect the simulation of soil state variables, whereas the simulated surface heat and water fluxes, as well as the snow depth, were significantly affected. For instance, the simulated runoff in CLASS-RNL is much higher than in CLASS-RNL-ObsP and CLASS-CTL at the most humid sites due to significant positive bias in ERA5 precipitation.
\end{abstract}

\section{Introduction}

Given their importance in climate regulation, much effort has been devoted to study boreal forests through numerous field experiments and modeling over the last decades (Whittaker and Likens 1973; Schlesinger 1991; Stocks et al. 1998; Bonan 2008). Despite their complexity, surface processes taking place in this ecosystem, such as soil moisture evolution, snow accumulation/melt, and

Corresponding author: Marco Alves, marco.alvarenga.alves@ gmail.com canopy interception, require an accurate representation in climate and weather prediction models (Sellers et al. 1997; Stocks et al. 1998; Bonan 2008). To this end, land surface models (LSMs) are typically used to simulate vertical exchanges of energy, mass, and momentum, and to provide boundary conditions for atmospheric and hydrological models (Letts et al. 2000; Abramowitz et al. 2008; Martynov et al. 2013; Weedon et al. 2014).

In general, an LSM requires time-invariant information for soil and vegetation properties and meteorological forcing for each time step of the simulation. Among LSMs, the Canadian Land Surface Scheme (CLASS) 
has been successfully tested, validated (e.g., Schlosser et al. 2000; Slater et al. 2001; Bowling et al. 2003; Rutter et al. 2009), and broadly applied over the North American boreal zone (e.g., Bartlett et al. 2000; Wang et al. 2001; Arain et al. 2002; Brown et al. 2006; Verseghy et al. 2017; Isabelle et al. 2018), as well as over other environments (e.g., Comer et al. 2000; Lafleur et al. 2000; Brown et al. 2006; Wen et al. 2007; Alves et al. 2019).

CLASS is frequently used in regional climate studies, serving as the land surface model in several climate models, such as the Canadian Atmospheric General Circulation Model and the Canadian Regional Climate Model (e.g., Music and Caya 2007; Martynov et al. 2013; Šparović et al. 2013; Whan and Zwiers 2016). In these studies, CLASS was fully coupled to an atmospheric model (Laprise et al. 2013; Von Salzen et al. 2013) responsible for providing its forcing meteorological data. Several recent studies have run CLASS in offline mode. In this instance, the user needs to prescribe the meteorological forcing. Admittedly, the uncoupled model disregards possible feedback between the surface and the adjacent atmosphere, but doing so allows the highlighting of the strengths and weaknesses in the simulation that originate exclusively from the LSM formulation (Verseghy et al. 2017). For instance, Brown et al. (2006) and Verseghy et al. (2017) have reported that CLASS could provide a realistic representation of snow processes over a range of climates. Wen et al. (2007) and Alves et al. (2019) have demonstrated that CLASS has an excellent ability to simulate surface energy fluxes at daily and monthly time scales, but that it has difficulty simulating realistic nocturnal heat fluxes (Alves et al. 2019). Recently, Isabelle et al. (2018) studied the sensitivity of evapotranspiration and soil moisture to the leaf area index of a boreal balsam fir canopy using CLASS in offline mode.

Selecting the meteorological forcing used to run an LSM in offline mode is not necessarily a trivial task. One option is to use direct observations of the surface conditions, as in Isabelle et al. (2018) and Alves et al. (2019), but the availability of continuous observed time series can easily become an issue. Meteorological reanalysis data, which combine data assimilation of direct or indirect measurements with model outputs (Dee et al. 2011), can then be a good alternative. Reanalyses provide gridded global datasets with a consistent spatial and temporal resolution, incorporating millions of observational data into a stable data assimilation system. Nevertheless, the quality of the LSM simulation driven by reanalysis data can be significantly affected by (local) biases in its forcing data. In particular, variables that not closely linked to the assimilated data, such as precipitation, should be used carefully (Dee et al. 2014).
Recently, the European Centre for Medium-Range Weather Forecasts (ECMWF) released ERA5, the fifth generation of its climate reanalysis, to replace, with several updates, the well-known ERA-Interim dataset (https://www.ecmwf.int/en/forecasts/datasets/reanalysisdatasets/era5, last access: 15 May 2019). ERA5 provides hourly estimates of a large number of atmospheric, land, and oceanic climate variables over a $31 \mathrm{~km} \times 31 \mathrm{~km}$ horizontal grid. Albergel et al. (2018) showed that ERA5 provided consistent improvement in the recent ECMWF's reanalysis compared to the ERA-Interim dataset in driving the LSM ISBA (Interactions between Soil, Biosphere, and Atmosphere) over the continental United States. They concluded that ISBA driven by ERA5 showed enhanced performance for land surface variables linked to the terrestrial hydrological cycle (i.e., soil moisture, snowpack depth, and turbulent heat fluxes), which was mainly due to improvements in the forcing precipitation data, while the outputs associated with vegetation (i.e., carbon uptake) were less impacted. Tarek et al. (2020) also highlighted the advantages of the ERA5 reanalysis compared to the ERA-Interim dataset for use in hydrological studies over North America. They concluded that the performance of ERA5-based hydrological modeling was equivalent to using observed data. Urraca et al. (2018) compared ERA5 data with the global climate reanalysis COSMO-REA6 for the estimation of surface irradiance. They determined that both products were better matched with satellite-based data than previous versions, but further development was required in the representation of clouds. They also argued that the spatial grid of ERA5 remains inadequate for coastal and mountainous applications.

Although the ERA5 reanalysis has a relatively coarse horizontal spatial resolution, it offers a consistent dataset of atmospheric surface conditions that could be used for various hydrometeorological studies, as demonstrated by Albergel et al. (2018), Tarek et al. (2020), and Urraca et al. (2018). However, further studies are needed to validate this dataset for various biomes and climate conditions.

In this study, we aim to evaluate the performance of CLASS driven by ERA5 (CLASS-RNL) in simulating surface energy fluxes, water exchanges, and snow and soil variables at few sites across the Canadian boreal forest. To do so, we compare results from CLASS-RNL simulations with available in situ measurements, as well as with results from CLASS control simulation (CLASSCTL), which is CLASS driven by observations. Moreover, we analyze the impacts of biases in the ERA5 precipitation data on the simulated land surface variables by adding another CLASS simulation driven by ERA5 data, but replacing the ERA5 precipitation by observed 


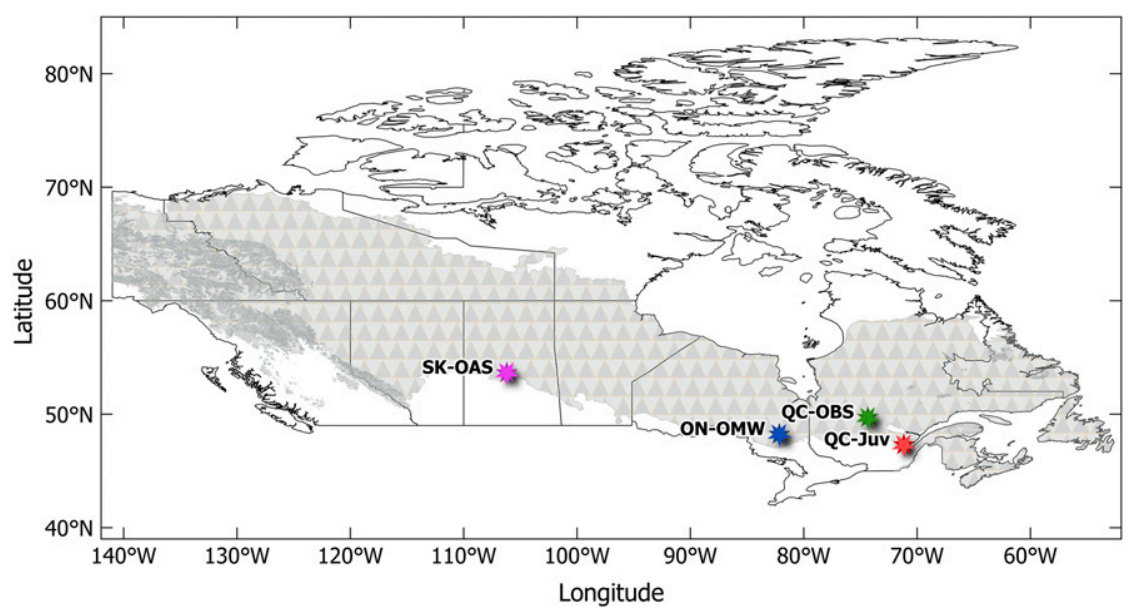

FIG. 1. Location of the study sites in the Canadian boreal forest (in light gray).

precipitation (CLASS-RNL-ObsP). We intend to focus on the ability of ERA5 to be used as meteorological forcing data over boreal regions, i.e., on assessing whether results from CLASS-RNL are comparable to CLASSCTL outputs and to in situ measurements. Note that all CLASS simulations are run at a local scale in the standalone version, $1 \mathrm{D}$ column.

\section{Datasets and study sites}

\section{a. Observational sites}

Four sites were selected to run CLASS over a multiyear period. These sites are located across Canada's boreal forest (Fig. 1) and were chosen for their diverse climate and extended data availability. One of these sites, the QC-Juv, located in the Montmorency Forest, Quebec (Canada), has been the focus of lesser studies given that its continuous micrometeorological observations began in October 2015 (Isabelle et al. 2018; Hadiwijaya et al. 2020). The other three sites investigated here (QC-OBS, ON-OMW, and SK-OAS) are part of the FLUXNET Canada Research Network (FLUXNET Canada Team 2016). The datasets include measurements of ancillary meteorological variables, turbulent fluxes of heat, water vapor and carbon dioxide, and soil and vegetation characteristics.

The QC-Juv (2016-18) and ON-OMW (2006-08) sites have 3 years of data, while the QC-OBS (2005-10) and SK-OAS (1997-10) have 6 and 14 years of continuous measurements, respectively. The surface measurement datasets for the four boreal sites were stored at a 30-min temporal resolution.

The principal characteristics of the sites are described in Table 1. The QC-Juv is the coldest and most humid site $(1444 \mathrm{~mm}$ mean annual total precipitation during the study period); SK-OAS is the driest (474 mm mean annual total precipitation), and ON-OMW is the warmest with a mean annual air temperature of $3.3^{\circ} \mathrm{C}$ and a mean annual soil temperature of $5.7^{\circ} \mathrm{C}$. Close to $32 \%$ of precipitation over QC-Juv and ON-OMW were in the solid form during the study period, while the other two sites (QC-OBS and SK-OAS) received smaller amounts of snow (approximately 23\% of the annual total precipitation).

Figure 2 displays the mean annual cycle of air temperature $\left(T_{a}\right)$, soil temperature $\left(T_{s}\right)$, rainfall (Rain), snowfall (Snow), and vapor pressure deficit (VPD) for the study period. As can be seen, the soil temperature at

TABLE 1. Characteristics of the study sites. The vegetation types (Veg.) are evergreen needleleaf forest (ENF), mixed forest (MF), and deciduous broadleaf forest $(\mathrm{DBF})$. Tree height $(\mathrm{m})$ is the average height of the dominant trees at each site. The mean annual variables and standard deviations (SD) are calculated for the study period only. MAP stands for mean annual total precipitation, MAS for mean annual snowfall, $\mathrm{MAT}_{a}$ for mean annual temperature, and $\mathrm{MAT}_{s}$ for mean annual topsoil temperature. Note that precipitation was separated into rain and snow using a temperature threshold of $0^{\circ} \mathrm{C}$.

\begin{tabular}{|c|c|c|c|c|c|c|c|c|}
\hline Site & $\begin{array}{c}\text { Location } \\
\text { (lat, lon, elev) }\end{array}$ & Veg. & $\begin{array}{c}\text { Tree } \\
\text { height }(\mathrm{m})\end{array}$ & $\begin{array}{l}\text { Study } \\
\text { years }\end{array}$ & $\begin{array}{l}\mathrm{MAP} \pm \\
\mathrm{SD}(\mathrm{mm})\end{array}$ & $\begin{array}{c}\text { MAS } \pm \\
\mathrm{SD}(\mathrm{mm})\end{array}$ & $\begin{array}{c}\operatorname{MAT}_{a} \pm \\
\mathrm{SD}\left({ }^{\circ} \mathrm{C}\right)\end{array}$ & $\begin{array}{l}\mathrm{MAT}_{s} \pm \\
\mathrm{SD}\left({ }^{\circ} \mathrm{C}\right)\end{array}$ \\
\hline QC-Juv & $47.29^{\circ} \mathrm{N}, 71.17^{\circ} \mathrm{W}, 825 \mathrm{~m}$ & ENF & $4-8$ & $2016-18$ & $1444 \pm 149$ & $464 \pm 3$ & $1.14 \pm 0.34$ & $4.74 \pm 0.32$ \\
\hline QC-OBS & $49.69^{\circ} \mathrm{N}, 74.34^{\circ} \mathrm{W}, 387 \mathrm{~m}$ & ENF & 14 & $2005-10$ & $850 \pm 192$ & $214 \pm 49$ & $2.28 \pm 0.90$ & $4.86 \pm 0.37$ \\
\hline ON-OMW & $48.22^{\circ} \mathrm{N}, 82.16^{\circ} \mathrm{W}, 340 \mathrm{~m}$ & MF & 24 & $2006-08$ & $826 \pm 45$ & $276 \pm 31$ & $3.30 \pm 0.97$ & $5.67 \pm 0.22$ \\
\hline SK-OAS & $53.63^{\circ} \mathrm{N}, 106.19^{\circ} \mathrm{W}, 601 \mathrm{~m}$ & DBF & 21 & $1997-10$ & $474 \pm 149$ & $109 \pm 36$ & $2.00 \pm 0.97$ & $4.53 \pm 0.51$ \\
\hline
\end{tabular}



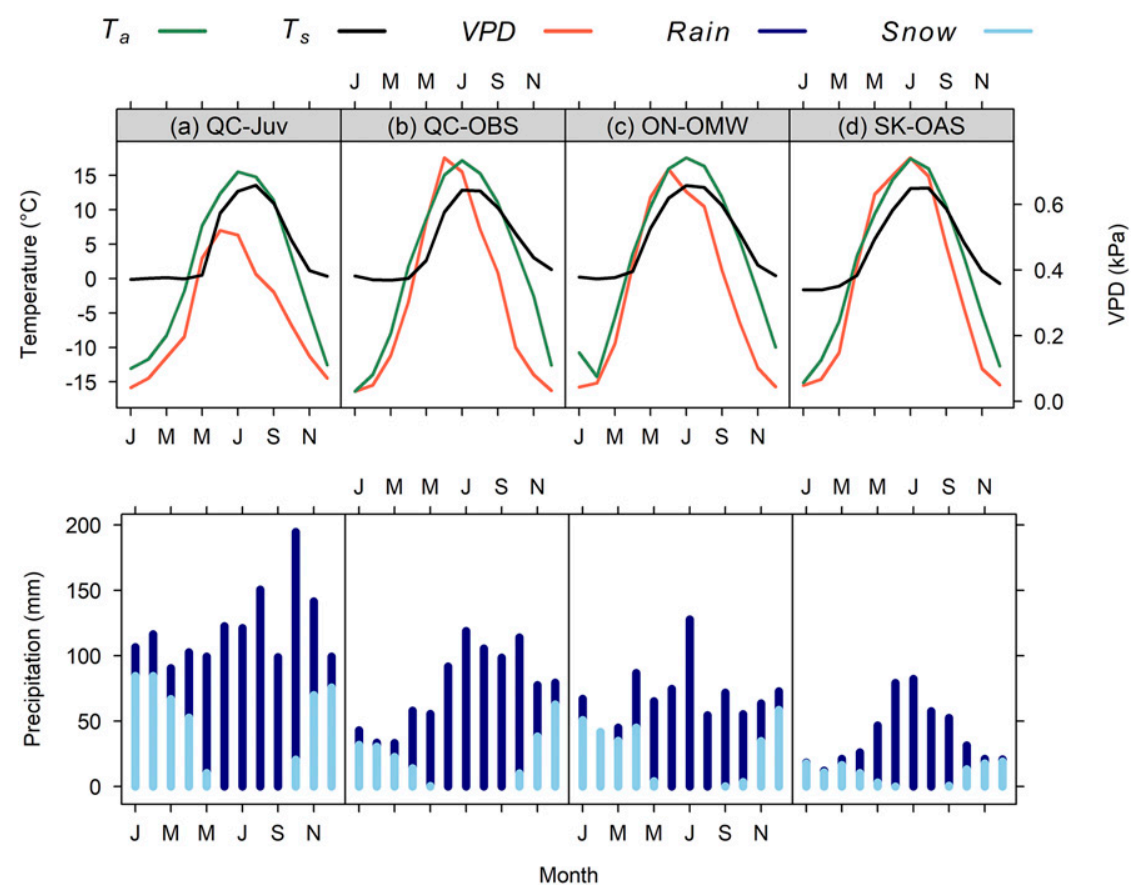

FIG. 2. Monthly mean variation at the studied boreal forest sites of air temperature above vegetation $\left(T_{a} ;{ }^{\circ} \mathrm{C}\right.$; green curves $)$, topsoil temperature $\left(T_{s} ;{ }^{\circ} \mathrm{C}\right.$; black curves), vapor pressure deficit (VPD; $\mathrm{kPa}$; orange curves), rainfall (Rain; $\mathrm{mm}$; dark blue vertical bars), and snowfall (Snow; mm; light blue vertical bars). The sites (a) QC-Juv, (b) QC-OBS, (c) ON-OMW, and (d) SK-OAS, are ranked from the wettest (left) to the driest (right) site. Note that precipitation was separated into rain and snow using a temperature threshold of $0^{\circ} \mathrm{C}$.

the sites shows similar intra-annual variations and amplitudes: it varies mostly between $0^{\circ}$ and $13^{\circ} \mathrm{C}$, except at SK-OAS that experiences frozen soil during the snow accumulation season (December-March; see Fig. 2d). In general, the soil starts warming up in April concomitant with snow melting and reaches its maximum in August (growing season). Note that at QC-Juv, the persistence of snow cover during the snowmelt season (April-May) keeps the soil cooler (with temperatures around $0^{\circ} \mathrm{C}$ ) than at the other sites (see Fig. 2a).

Precipitation varies substantially within the year (Fig. 2). The QC-Juv and ON-OMW sites have more uniform precipitation regimes throughout the year, with rainfall maxima in August and October at QC-Juv, and in July at ON-OMW (Figs. 2a,c). The precipitation at QC-OBS and SK-OAS is, in general, more substantial during the warmer months (Figs. 2b,d).

\section{b. Meteorological forcing: ERA5 reanalysis dataset}

The most recent ECMWF's reanalysis product, the ERA5, is under the framework of the European funded Copernicus Climate Change Services (C3S). The ERA5 reanalysis offers a detailed overview of the atmosphere from 1950 onward, with a horizontal spatial resolution of approximately $31 \mathrm{~km} \times 31 \mathrm{~km}, 137$ levels in the vertical direction, and a temporal resolution of $1 \mathrm{~h}$ (Hersbach et al. 2018).

The ERA5 reanalysis uses the most recent ECMWF's integrated forecast system (IFS Cycle 41r2) in an optimized version to best use data provided by the current observing system (Hersbach et al. 2018). The reanalysis integrates the IFS Cycle 41r2 with worldwide weather records into a globally complete and stable dataset via data assimilation, concomitantly constrained by physical laws (Hersbach et al. 2018; Jiang et al. 2020). The data assimilation is realized through a four-dimensional variational assimilation system (4D-Var) that reanalyzes the archived meteorological observations with a 12-h window and evaluates the equipment and operational biases between the observations. The physical laws described in the ECMWF forecast model (IFS Cycle 41r2) allow for estimating meteorological variables outside existing stations where data coverage is unavailable, e.g., the surface temperature in the northernmost region of the Canadian boreal forest. The physical laws applied to land surface processes are represented in the ECMWF forecast model by the Tiled ECMWF Scheme for Surface Exchanges over Land (TESSEL) with a revised land surface hydrology (HTESSEL, Balsamo et al. 2009). The HTESSEL is a sophisticated land surface model, with a concept similar to 
CLASS, and its task is to represent the surface fluxes of energy and water and, where appropriate, corresponding subsurface quantities in the ECMWF forecast model (more information at https://www.ecmwf.int/en/elibrary/ 16648-part-iv-physical-processes, accessed December 2019). The LSM divides the relatively thin layer of interface between the surface and atmosphere into fractions (tiles), with up to six fractions over land (bare ground, low and high canopy, shaded and exposed snow, and intercepted water) and up to two fractions over sea and freshwater, with separate energy and water budget calculation (Balsamo et al. 2009). It is important to highlight that the simulation of surface variables by the HTESSEL model may particularly affect the ERA5 variables that are not assimilated in the model; the assimilated variables should be less sensitive to the LSM and can, therefore, be considered as pseudo-observations.

The ERA5 data were obtained from Copernicus Climate Change Service (https://cds.climate.copernicus.eu, accessed 1 February 2019). Meteorological data were retrieved for the lowest atmospheric level (surface level) of each ERA5 grid cell encompassing the study sites. In other words, we used the nearest-neighbor approach to assign meteorological forcing to each of our study sites using the ERA5 global dataset.

In total, four ERA5 datasets were obtained and consist of hourly values of incoming shortwave and longwave radiation, 2-m air temperature and specific humidity, total precipitation, zonal and meridional components of the wind speed $10 \mathrm{~m}$ above ground, and surface pressure. The incoming shortwave and longwave radiation and total precipitation data are purely forecasted variables of the ERA5 atmospheric model. In contrast, the other variables combine predicted values with direct and indirect measurements (assimilated data).

The hourly values of incoming longwave radiation, air temperature, specific humidity, and surface pressure from the ERA5 dataset were vertically adjusted to account for differences in elevation between the ERA5 grid and the flux tower sites. The approach applied follows closely the methodology proposed by Cosgrove et al. (2003).

The first variable to be revised was ERA5 air temperature; the correction method is based on the relationship between the elevation and air temperature, assuming a constant value of the environmental lapse rate of $-6.5 \mathrm{~K} \mathrm{~km}^{-1}$. Subsequently, the surface pressure, specific humidity, and incoming shortwave radiation were adjusted based on their relationship with the air temperature.

After the elevation adjustment in the ERA5 grid at each study site, the ERA5 datasets were resampled to half-hourly values using linear interpolations, except for precipitation values, since $30 \mathrm{~min}$ is the required time step to run the CLASS model. Hourly values of the total precipitation rate were considered constant over every two time steps of $30 \mathrm{~min}$.

\section{Canadian Land Surface Scheme, version 3.6}

CLASS is a sophisticated land surface model based on fundamental physical laws that govern the transfer of energy and water between the land surface and the atmosphere (Verseghy 1991; Verseghy et al. 1993). Version 3.6, released in 2011, allows a flexible number of soil layers (Verseghy 2012) and includes updates in the parameterization snow interception by vegetation, snow unloading from vegetation, and snow melting processes, such as snow albedo refreshment and snow thermal conductivity.

CLASS considers distinct energy and water balances for soil, vegetation, and snowpack. The vertical energy and water fluxes are calculated every $30 \mathrm{~min}$ for four subareas: bare soil, vegetation over bare soil, vegetation with snow cover, and snow over bare soil. Fluxes are averaged over each subarea. CLASS uses attributes and properties of four broad vegetation types (needleleaf trees, broadleaf trees, crops, grass) for the vegetated subareas (Verseghy et al. 2017).

CLASS requires seven meteorological variables as forcing data: incoming shortwave and longwave radiation, total precipitation rate, air temperature, air specific humidity, wind speed (all at reference height), and surface atmospheric pressure (Verseghy 2012). Several fixed parameters mainly related to vegetation and soil features are also required.

The standard partitioning of total precipitation rate into rain and snow in CLASS uses an air temperature threshold: above $0^{\circ} \mathrm{C}$, all precipitation falls as rain and below $0^{\circ} \mathrm{C}$ as snow. The interception of snowfall by the canopy is explicitly simulated, with the interception (or "storage") capacity of the vegetation depending on the canopy leaf area index. The ground is considered to be ultimately snow-covered when the snowpack depth is equal to or greater than $0.10 \mathrm{~m}$; if it is less than this threshold, the snow depth is set to $0.10 \mathrm{~m}$, and the fractional snow cover is determined based on the conservation of snow mass (Verseghy 2012; Verseghy et al. 2017).

The snowpack built upon the ground as a result of snowfall and favorable atmospheric conditions, with air temperature consistently below $0^{\circ} \mathrm{C}$, is simulated as a single layer thermally separated from the soil underneath. The simulated snowpack state variables in CLASS include snow surface temperature, mean snowpack temperature, snow albedo, mean snowpack density, snow water equivalent, and liquid water content. The snow 
TABLE 2. Parameters used in the CLASS version 3.6 for this study. ENF = evergreen needleleaf forest and DBL $=$ deciduous broadleaf forest.

\begin{tabular}{|c|c|c|c|c|c|}
\hline \multirow[b]{2}{*}{ Parameter/variable } & \multicolumn{5}{|c|}{ Sites } \\
\hline & QC-Juv & QC-OBS & \multicolumn{2}{|c|}{ ON-OMW } & $\overline{\text { SK-OAS }}$ \\
\hline \multicolumn{6}{|c|}{ Vegetation } \\
\hline Fractional coverage $(\%)$ & $90^{\mathrm{ENF}}$ & $80^{\mathrm{ENF}}$ & $50^{\mathrm{ENF}}$ & $50^{\mathrm{DBL}}$ & $95^{\mathrm{DBL}}$ \\
\hline Roughness length (m) & 1.039 & 1.793 & 1.499 & 1.999 & 2.611 \\
\hline Max leaf area index $\left(\mathrm{m}^{2} \mathrm{~m}^{-2}\right)$ & 2.9 & 3.7 & 3.6 & 2.4 & 6.0 \\
\hline Min leaf area index $\left(\mathrm{m}^{2} \mathrm{~m}^{-2}\right)$ & 1.5 & 0.5 & 1.6 & 0.5 & 0.25 \\
\hline Aboveground canopy mass $\left(\mathrm{kg} \mathrm{m}^{-2}\right)$ & 22.4 & 20.0 & 25.0 & 20.0 & 20.0 \\
\hline Rooting depth (m) & 0.3 & 0.4 & 0.5 & 0.5 & 0.3 \\
\hline \multicolumn{6}{|c|}{ Soil } \\
\hline Soil depth (m) & 1.0 & 1.0 & \multicolumn{2}{|c|}{0.5} & 1.0 \\
\hline Sand $(\%)$ & 60.0 & 85.0 & \multicolumn{2}{|c|}{5.0} & 48.0 \\
\hline Clay (\%) & 15.0 & 5.0 & \multicolumn{2}{|c|}{65.0} & 10.0 \\
\hline Organic matter (\%) & 2.0 & 1.0 & \multicolumn{2}{|c|}{1.0} & 1.0 \\
\hline
\end{tabular}

albedo and snow density are estimated from empirically derived functions from fresh snow values that decrease exponentially with time (Longley 1960; Dirmhirn and Eaton 1975; Aguado 1985; Robinson and Kukla 1984; Verseghy 2012). The new snow density is determined from an empirical function of air temperature (Pomeroy and Gray 1995; Hedstrom and Pomeroy 1998). Snow thermal conductivity is obtained from snow density using the empirical relationship derived by Sturm et al. (1997).

Melting of the snowpack can take place either from heat exchanges at its surface (as a response to energy fluxes with the air and canopy above) or at its base (as a response to soil heat fluxes). Snowpack temperature is reset to $0^{\circ} \mathrm{C}$, and the excess energy is used for melting the snowpack when the simulated snowpack surface temperature exceeds the freezing point. Percolation and refreezing of meltwater in the snowpack occurs until the snow is isothermal at $0^{\circ} \mathrm{C}$, after which meltwater can infiltrate into the soil (Brown et al. 2006; Verseghy et al. 2017).

\section{a. Model setup}

Three CLASS simulations (CTL, RNL, and RNLObsP) sharing a standard parameter file (Table 2) were generated for each study site, but with different meteorological forcing data. Figure 3 shows a schematic diagram to exemplify each CLASS simulation. Note that we used a stand-alone, $1 \mathrm{D}$ column CLASS version to execute land surface simulations for each site investigated.

The first CLASS simulation (CTL) used observations as forcing data, thus allowing us to evaluate CLASS's ability to simulate energy fluxes and hydrological conditions when driven by the most accurate meteorological

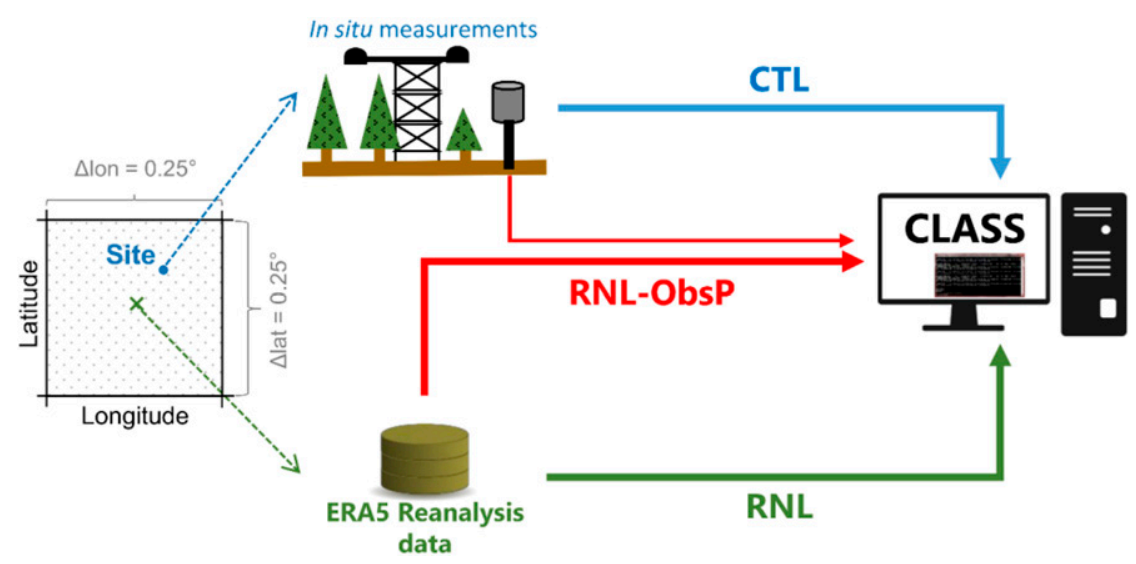

FIG. 3. Schematic diagram of the CLASS simulations realized for each study site. Each experimental site has a set of instruments to provide in situ measurements that are used to drive CTL simulation. ERA5 reanalysis data, with a horizontal grid resolution of $0.25^{\circ} \times 0.25^{\circ}$, were retrieved from the grid encompassing each study site and are used to drive RNL and RNLObsP simulations. The latter had observed precipitation replacing the same variable from the ERA5 data set. 
forcing available. The second used ERA5 reanalysis data for this purpose (hence its RNL label), allowing us to highlight the impact of using reanalyses as forcing data on the performance of CLASS. The forcing data for the third CLASS simulation came from ERA5, except for the total precipitation rate, which was taken from observations (hereafter RNL-ObsP). The latter is used to help us to better understand whether the positive/negative bias in ERA5 precipitation affects the performance of CLASS.

The main parameters that describe the vegetation and the soil features at each site for the three CLASS runs are shown in Table 2. Some of the values presented in the table (e.g., fractional coverage, above canopy mass, rooting depth, and leaf area index) were taken from previous studies for each site (Steele et al. 1997; Cox et al. 2000; Chen et al. 2006; McCaughey et al. 2006; Bergeron et al. 2007; Isabelle et al. 2018). Standard values suggested in CLASS documentation (Verseghy 2012) were used for parameters that were not measured or described in the cited literature.

As for soil description, the soil column and organic layer depths were kept constant throughout the simulations. It was divided into 16 fixed soil layers (defined at depths of $0.1,0.3,0.6,1.0,1.5,2.0,2.5,3.0,3.5,4.0,4.5$, 5.0, 5.5, 6.0, 7.0 and $10.0 \mathrm{~m}$ ), with the top 10-cm layer representing the organic soil layer.

Furthermore, 2.5 years of data, starting on 1 July (under snow-free condition), were given as spinup for initializing each CLASS simulation, thus allowing the model to reach an equilibrium in soil moisture and soil temperature. The spinup data come from the first years of each input dataset. Note that the simulated results referring to the spinup data were disregarded for the analyses of the results.

\section{Results and discussion}

\section{a. Local-scale validation of ERA5 data}

A natural first step before starting the modeling process is to evaluate the correspondence between ERA5 data, i.e., a pseudo-observation dataset, and in situ measurements at the local scale. As mentioned previously (sections $2 \mathrm{a}$ and $2 \mathrm{~b}$ ), we should keep in mind that there are scale mismatches between the ERA5 data and point observations. Therefore, the underlying assumption in the evaluation is that the surface variables retrieved from ERA5 grids encompassing the studied sites are a good approximation of the meteorological conditions for the investigated sites where observational instruments have been installed.

Figure 4 compares 30-min data for all variables except for total precipitation, for which daily cumulative values are presented instead in order to improve the relationship
(Fig. 4g). Indeed, ERA5 precipitation at all sites was more comparable with observations at the daily scale, with the coefficient of determination $\left(r^{2}\right)$ around 0.6, than at hourly or half-hourly intervals $\left(r^{2} \approx 0.1\right.$, results not shown).

In general, the ERA5 data are well correlated with local observations. The incoming shortwave/longwave radiation, air temperature, air specific humidity, and surface air pressure all show $r^{2}$ values greater than 0.73 and a relative bias smaller than $7 \%$. Lower correlations are found when comparing the observed and ERA5 wind speed $\left(r^{2}=0.54\right.$ and relative bias $\left.=14.6 \%\right)$ and total daily precipitation $\left(r^{2}=0.60\right.$ and relative bias $\left.=14.2 \%\right)$.

Although the ERA5 variables are well correlated with observations, some discrepancies with the in situ measurements are notable. For instance, the incoming shortwave radiation and total precipitation comparisons show significant scattering. The biases in wind speed are partly because reference levels from in situ measurements and ERA5 data do not match exactly with each other, and because this variable varies considerably in space.

Precipitation is generally overestimated by ERA5 (Fig. 4g). At the annual scale, positive biases occur at the SK-OAS (relative bias $=18.4 \%, 87 \mathrm{~mm}$ ), QC-OBS (relative bias $=15.3 \%, 138 \mathrm{~mm}$ ), and QC-Juv (relative bias $=14 \%, 202 \mathrm{~mm}$ ) sites. A higher annual amount of precipitation from ERA5 data is observed for the most humid sites (QC-Juv, $202 \mathrm{~mm}$; QC-OBS, $138 \mathrm{~mm}$ ). For ON-OMW, the annual bias reaches $20 \mathrm{~mm}$, which represents only $2.4 \%$ of the observed mean annual amount. At all sites, larger biases in ERA5 precipitation and lower correlations with observations occur from June to September (not shown). These can be associated with the ERA5 atmospheric model's limited ability in predicting convective storms, which are very common in the warm season (Cao and Zhang 2016; Prein et al. 2017). Note that the reliable representation of precipitation in reanalysis products represents a special challenge because it involves many small-scale processes and, consequently, biases in reanalyses data are widely reported in the literature (Adler et al. 2003; Simmons et al. 2010; Dee et al. 2011; Boisvert et al. 2018; Rustemeier et al. 2019).

Undoubtedly, the discrepancies between the ERA5 data and observations, though small for some variables, may be partly explained by the spatial-scale mismatch between these datasets. We should recall that for some forcing variables (incoming longwave radiation, air temperature, specific humidity, and surface pressure), possible discrepancies between the ERA5 and in situ measured variables were reduced by vertically adjusting the ERA5 grid to the same elevation level of the individual sites-see Cosgrove et al. (2003) for a full description of the methodology applied. Hence, the results presented in 

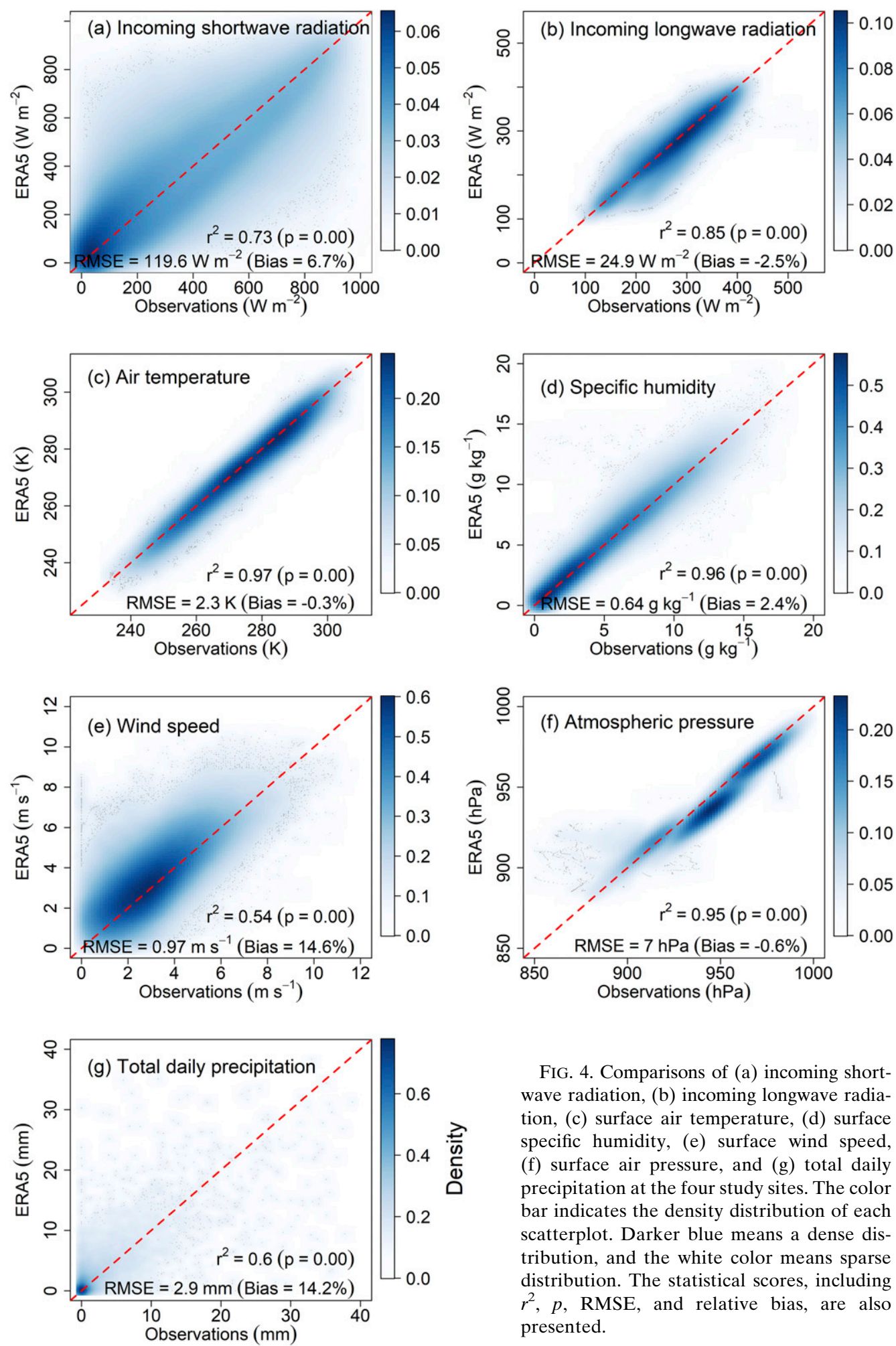

FIG. 4. Comparisons of (a) incoming shortwave radiation, (b) incoming longwave radiation, (c) surface air temperature, (d) surface specific humidity, (e) surface wind speed, (f) surface air pressure, and (g) total daily precipitation at the four study sites. The color bar indicates the density distribution of each scatterplot. Darker blue means a dense distribution, and the white color means sparse distribution. The statistical scores, including $r^{2}, p$, RMSE, and relative bias, are also presented. 

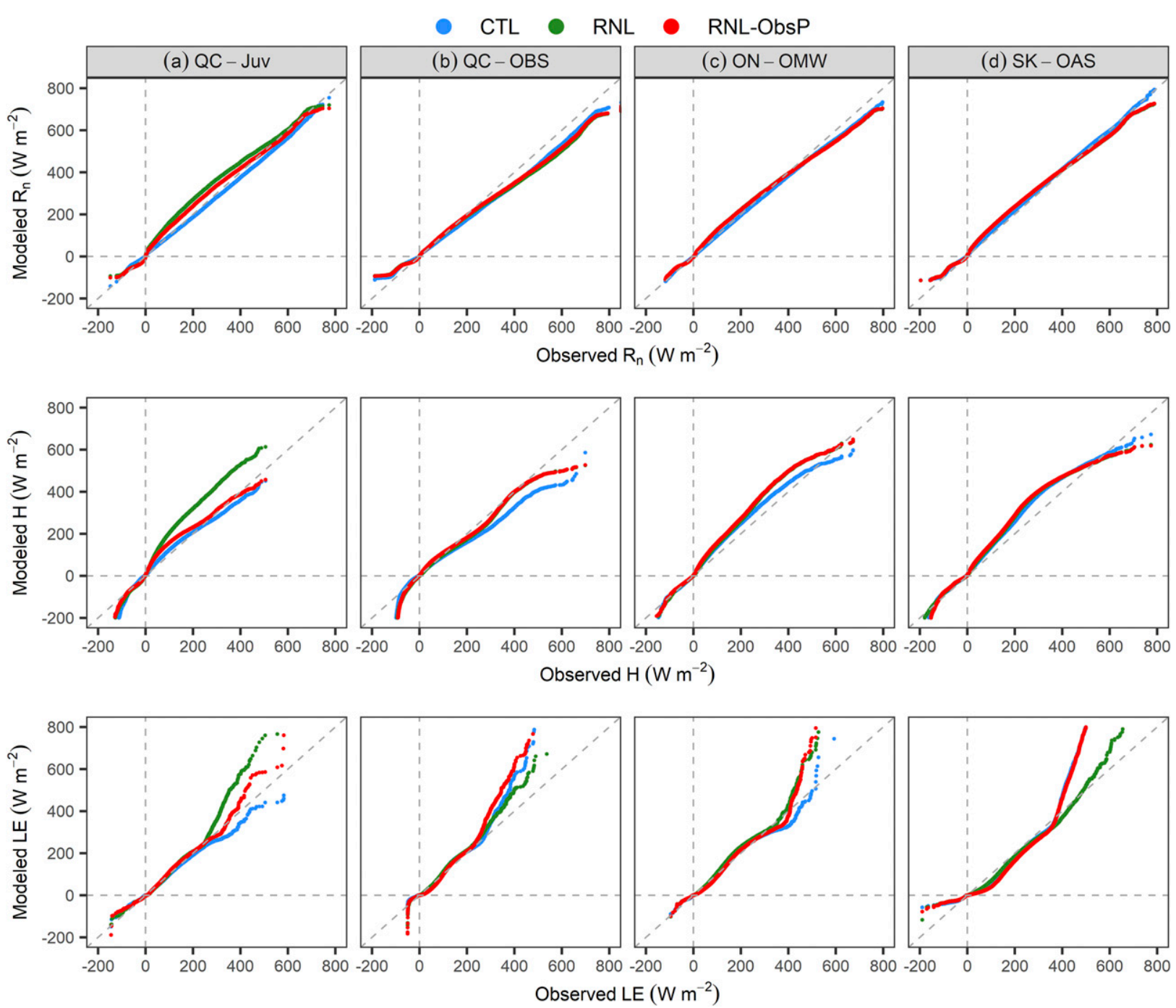

FIG. 5. Quantile-quantile (QQ) plots of observed and modeled surface net radiation $\left(R_{n} ; \mathrm{W} \mathrm{m}^{-2}\right)$, sensible heat flux $\left(H ; \mathrm{W} \mathrm{m}^{-2}\right)$, and latent heat flux (LE; $\mathrm{W} \mathrm{m}^{-2}$ ) at the four sites: (a) QC-Juv, (b) QC-OBS, (c) ON-OMW, and (d) SK-OAS. Blue, green, and red points are from QQ plots of observations vs CTL, RNL, and RNL-ObsP simulations, respectively. The plots are based on 30-min data over multiple years of interest.

the following subsections show how the discrepancies in the meteorological forcing for CLASS runs are translated to the simulated land surface processes, such as the surface energy and water fluxes.

\section{b. Overall performance of simulated surface energy fluxes}

Figure 5 compares quantiles of net radiation $\left(R_{n}\right)$, sensible heat flux $(H)$, and latent heat flux (LE) at 30-min time intervals derived from the CLASS simulations (CTL, RNL, and RNL-ObsP) with in situ observations over the full study period at each site. Note that the quantile-quantile plots, used to compare the overall distribution of the modeled and observed variables, does not account for time in its dimensions; this means that the maximum values of $R_{n}$ do not necessarily occur at the same time step as the $H$ and LE maxima and vice versa. In general, all three CLASS simulations agree with each other. The three simulations well capture observed $R_{n}$ (data points are close to the 1:1 line) at all sites. The remarkable performance of CLASS to simulate net radiation has also been highlighted by Wen et al. (2007) and Alves et al. (2019).

Generally, CLASS simulations of sensible heat flux show good performance, but with slight overestimations at QC-Juv, ON-OMW, and SK-OAS (Figs. 5a,c,d), and a slight underestimation at QC-OBS (Fig. 5b). These biases are mainly seen at observed $H$ values greater than $200 \mathrm{~W} \mathrm{~m}^{-2}$, which usually occurs during snowmelt (April-May) due to an increase in solar 

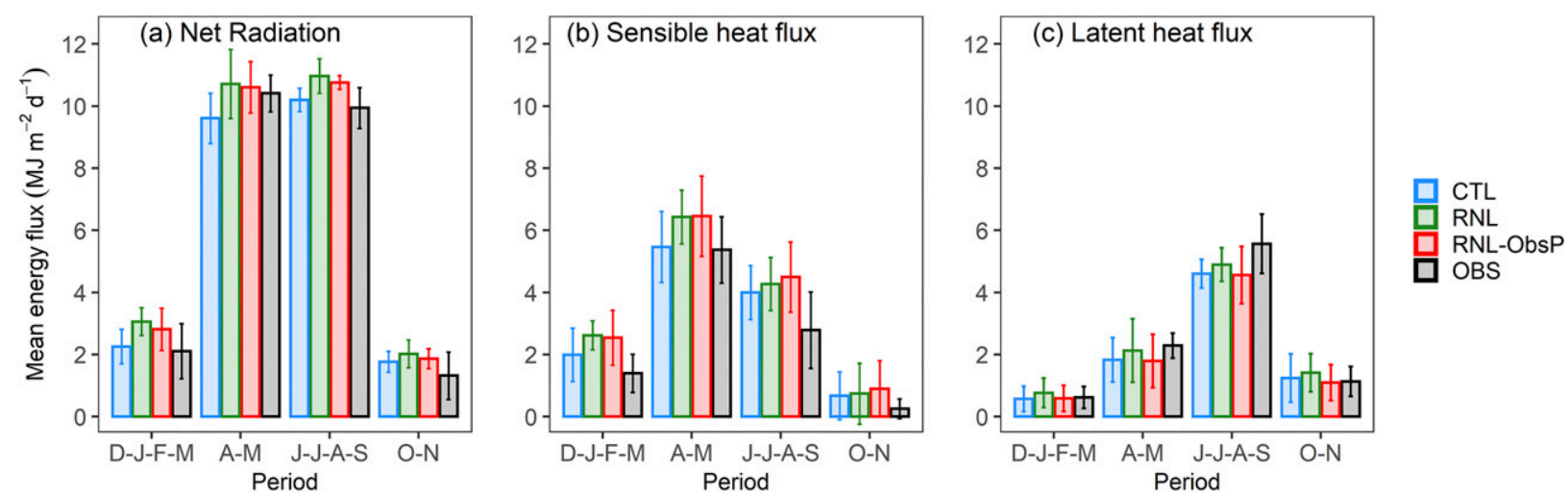

FIG. 6. Mean seasonal variation of (a) surface net radiation $\left(\mathrm{MJ} \mathrm{m}^{-2} \mathrm{day}^{-1}\right)$, (b) sensible heat flux $\left(\mathrm{MJ} \mathrm{m}^{-2} \mathrm{day}^{-1}\right)$, and (c) latent heat flux $\left(\mathrm{MJ} \mathrm{m}^{-2} \mathrm{day}^{-1}\right)$ at the boreal sites investigated in this study. Error bars represent the standard deviation calculated by pooling the seasonal mean values for each study site.

radiation availability and favorable atmospheric conditions. Overall, the RNL simulation is quite comparable to CTL, although differences are observed toward the upper quantiles at QC-Juv, QC-OBS, and ON-OMW (Figs. 5a-c). These dissimilarities are striking at the QC-Juv site, where the sensible heat flux simulated by CLASS-RNL deviates substantially from CLASS-CTL results, with differences up to about $200 \mathrm{~W} \mathrm{~m}^{-2}$. The overestimation of precipitation from the ERA5 reanalysis at QC-Juv plays an essential role in the difference between the RNL and CTL simulations, and this difference is minimized when comparing the control simulation (CTL) with RNL-ObsP simulation (Fig. 5a).

CLASS overestimates the upper quantiles of the latent heat flux, which, favored by transpiration processes, mostly occur during the growing season (from June to September). Generally, the RNL and CTL simulations are quite comparable with each other for latent heat fluxes smaller than $400 \mathrm{~W} \mathrm{~m}^{-2}$. Larger differences due to different forcing (precipitation) data (Figs. 5a,d) appear, however, for more significant fluxes, particularly at QC-Juv (Fig. 5a) and SK-OAS (Fig. 5d). For instance, the simulated LE values from CLASS-CTL were largely overestimated at the SK-OAS site, possibly due to errors in the measurement of precipitation. In addition, the simulated LE from RNL-ObsP and CTL are similar to each other but, for observed LE values above $\approx 400 \mathrm{~W} \mathrm{~m}^{-2}$, are noticeably different from the LE values generated by the RNL simulation, suggesting that precipitation is the primary driver of these biases (Fig. 5d). Overall, the consistent overestimation of large LE fluxes at the four study sites is mainly present at a $30-\mathrm{min}$ time scale. At a daily scale, the simulated and observed LE values are, in general, more comparable to each other (results not shown).

In general, negative fluxes of simulated $R_{n}$ and $H$ better capture the observations than those of LE. For negative values of LE, the simulated and observed values are in better agreement for the QC-Juv and ONOMW sites.

Figure 6 illustrates the mean simulated and observed values of the surface heat fluxes at all sites, grouped by different periods of the year, which were based on the variation of the monthly mean air temperatures (see Fig. 2). The seasons of the year are divided into four groups: DJFM = December-March (snow accumulation season); AM = April-May ( June-September (growing season); ON = OctoberNovember (cooling season). During the snow accumulation and cooling periods, observed $R_{n}$ is, on average, around 2.1 and $1.3 \mathrm{MJ} \mathrm{m}^{-2} \mathrm{day}^{-1}$, respectively. However, due to prolonged sunshine hours in the spring and summer periods, it reaches average values of about $\approx 10.0 \mathrm{MJ} \mathrm{m}^{-2} \mathrm{day}^{-1}$. The simulated mean values of $R_{n}$ from RNL simulations are in good agreement with observations (differences varying on average by $\approx 0.75 \mathrm{MJ} \mathrm{m}^{-2} \mathrm{day}^{-1}$ ) and with the CTL results (differences varying on average by $\approx 0.74 \mathrm{MJ} \mathrm{m}^{-2} \mathrm{day}^{-1}$ ). In other words, CLASS driven by ERA5 reanalysis can provide a reasonable estimation of the mean value of $R_{n}$ throughout the year.

During the snow accumulation and snowmelt periods, the average values from observations show that, respectively, $66 \%$ and $52 \%$ of $R_{n}$ is converted into sensible heat flux. In general, this seasonal variation in $H$ is well captured by all three CLASS simulations. However, simulated $H$ suffers from overestimation (Fig. 6b), as previously reported in Fig. 5 for the QC-Juv, ON-OMW, and SK-OAS sites.

CLASS also shows excellent performance in simulating the seasonal variation in the latent heat flux with observed and ERA5 forcing data (CTL and RNL). Although the simulation of LE is generally 

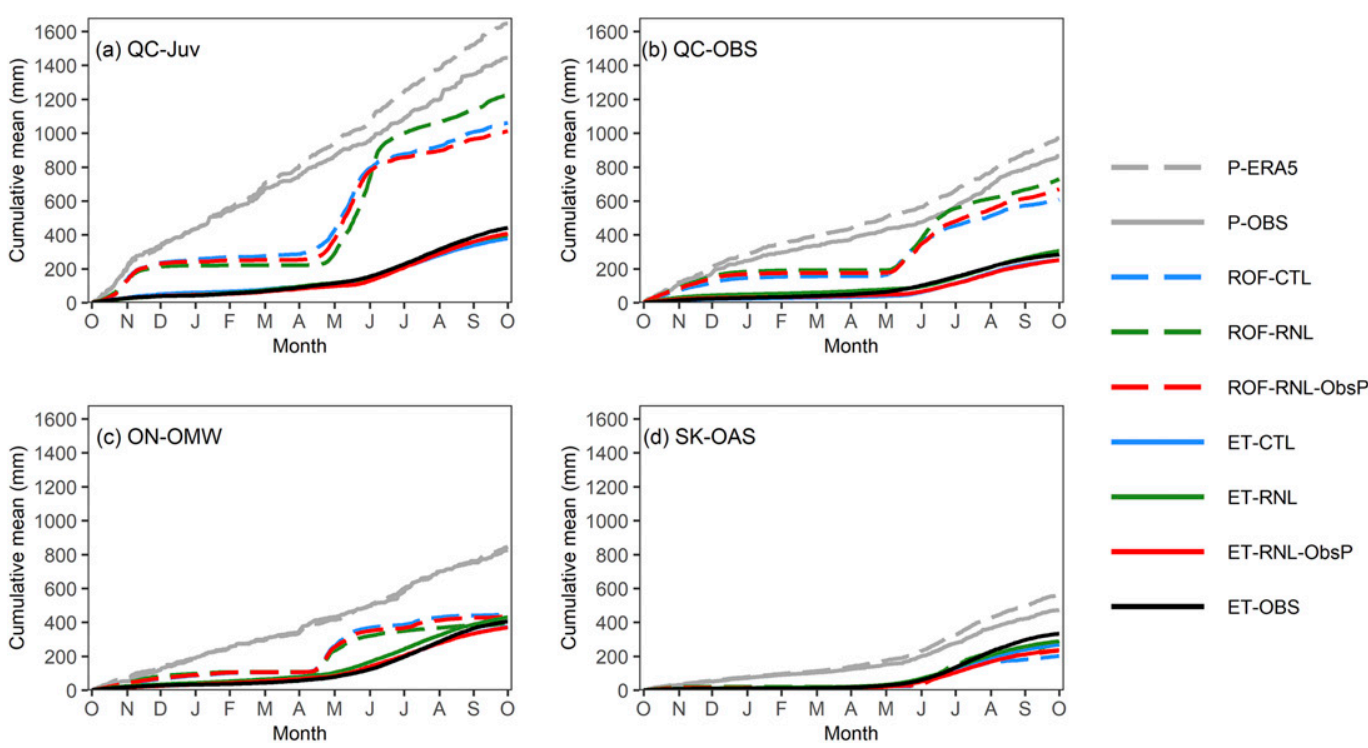

FIG. 7. Cumulative mean values of the water balance components over a hydrological year (12-month period starting on 1 Oct) at the (a) QC-Juv, (b) QC-OBS, (c) ON-OMW, and (d) SK-OAS sites. Gray lines represent total precipitation from ERA5 reanalysis (long dash lines) and observations (solid lines). Blue, green, and red lines represent produced total runoff (long dash lines) and evapotranspiration (solid lines) from CTL, RNL, and RNLObsP simulations, respectively. Black solid lines represent evapotranspiration from observations.

overestimated by CLASS at the 30-min temporal scale (see Fig. 5), the simulated seasonal mean values, calculated from the daily mean values, from all three CLASS runs are quite close to the LE mean values from observations and are confined within the range of the standard deviation values. However, small biases between simulated mean values from CLASSRNL and CLASS-CTL driven by underestimations should be noted for the ON-OMW and SK-OAS sites, especially during the growing season (results not shown). These biases are associated with differences between precipitation data from ERA5 and observations since CLASS-RNL-ObsP shows results closer to CLASS-CTL than to the CLASS-RNL.

Net radiation from observations is not partitioned entirely into $H$ and LE at the sites. For example, the turbulent heat fluxes ( $H$ and LE) account for about $81 \%$ of the net radiation (Pearson correlation $\approx 0.95$ ) at the QC-OBS, ON-OMW, and SK-OAS sites, whereas they represent only $69 \%$ of the net radiation (Pearson correlation $\approx 0.93$ ) at QC-Juv (results not shown). We must remind the reader that soil heat flux, disregarded in our analysis due to a lack of data availability, also contributes to surface energy closure, although this contribution is typically small for forested sites (e.g., Purdy et al. 2016). Also, in situ net radiation and turbulent heat fluxes measurement errors due to various factors (e.g., snow accumulation on the sensor, extreme precipitation events, and energy advection) should be taken into consideration when attempting to estimate surface energy partitioning from observations (Nordbo et al. 2012; Anderson and Wang 2014).

\section{c. Sensitivity analysis of simulated water balance terms}

Cumulative mean values of the main water balance components over a hydrological year at the four study sites are presented in Fig. 7: total precipitation $(P)$ values from ERA5 reanalysis and observations, as well as simulated total runoff (ROF) and simulated and observed evapotranspiration (ET). At all sites, CLASS-RNL is able to reproduce the partitioning of precipitation into ROF and ET modeled by CLASSCTL. Also, the simulated cumulative values of ET agree with observations.

Precipitation is mainly converted $(\approx 70 \%)$ into ROF (overland flow and base flow from the bottom of the soil column) at the most humid sites (QC-Juv and QC-OBS, Figs. 7a and 7b), while this ratio is reduced to about $40 \%-50 \%$ at the warmest (ON-OMW, Fig. 7c) and driest (SK-OAS, Fig. 7d) sites, where the evapotranspiration processes are more dominant than at the humid sites. Zheng et al. (2019) used the Noah land surface model with multiparameterization options to study the sensitivity of precipitation partitioning in the parameterizations of ROF and ET over the United States. They also concluded that precipitation is mostly partitioned into ROF for humid regions, whereas ET accounts for a 
significant part of the precipitation partitioning in drier regions. The ROF results are more sensitive to ET's parameterization and vice versa.

As to total runoff partitioning performed by CLASS simulations, the base flow from the bottom of the soil column (drainage) is the dominant component at all sites. This drainage term represents $100 \%$ of the ROF at the most humid sites (QC-Juv, QC-OBS, ON-OMW) and $\approx 90 \%$ at the driest site (results not shown). Unfortunately, there were no in situ measurements of runoff at the study sites to validate these simulation findings.

Similar results have been presented by Arora and Boer (2002), who showed that, while CLASS simulates well the globally averaged total runoff over land, it fails in the partitioning of this term. The authors reported that the simulated ROF partitioning shows a more substantial fraction $(\approx 77 \%)$ of water going to the bottom of the permeable soil by the drainage term. At the same time, L'vovich (1979) estimates suggest that surface runoff (overland streamflow) represents a more significant overall portion of total runoff $(\approx 70 \%)$. Wen et al. (2007) proposed a modification in CLASS version 2.7 that allows for interflow of soil moisture since the standard model only accounts for the vertical movement of water in the soil. The authors contrasted this modified version with the traditional CLASS, and they concluded that their improved version was able to preserve the existent positive features of the model (high-performance simulation of the surface heat fluxes, temperature, soil moisture, and runoff) while improving the simulation of peak flows and flood timing. The interflow parameterization of soil moisture is, however, neglected in CLASS version 3.6.

The cumulative mean values of water budget terms from CLASS-RNL and CLASS-CTL are very similar to each other (Fig. 7c) at ON-OMW, where the mean bias of ERA5 precipitation compared to observations is close to zero. On the other hand, the modeled ROF and ET from CLASS-RNL deviate considerably from the CLASS-CTL results, particularly from April to September (from snowmelt to growing season) at the humid sites (QC-Juv and QC-OBS), where the ERA5 precipitation biases are significant, and the extra water from ERA5 precipitation goes mainly to ROF $(\approx 80 \%$ at QC-Juv and $\approx 70 \%$ at QC-OBS). Moreover, ROF and ET values from CLASS-RNL-ObsP tend to be closer to the CLASSCTL results, which again highlights that the differences in precipitation are the main reason for biases.

\section{d. Simulation of snowpack state variables}

All sites studied have snow on the ground for at least five months of the year. Time series of the daily values of modeled versus observed snow depth are presented in
Fig. 8. In general, results from CLASS driven by ERA5 and observations agree quite well with each other and, as shown in Table 3, are generally in good agreement with the observations of snowpack depth. Admittedly, the positive results of the comparison between simulated and observed snowpack depth are focused on the main trends of snowpack properties, such as the periods of maximum snow depth and duration of the ablation period. The snowpack depth simulation in boreal forests must be carefully compared to in situ observations due to its high-spatial variability across the vegetated surfaces (Jost et al. 2007; Metcalfe and Buttle 1998). Furthermore, biases in ERA5 precipitation data, as discussed in section $4 \mathrm{a}$, are mainly responsible for the differences between CLASS-RNL and CLASS-CTL results, especially at the most humid sites (QC-Juv and QC-OBS); hence, the CLASS-RNL-ObsP shows results comparable to CLASS-CTL (Table 3).

First, the snow depth measurements at the QC-Juv site were likely overestimated because the sensor was placed in a small forest opening where snow accumulation was higher, in part due to less interception than under the canopy. On average, the maximum value of accumulated snow from observations is $1.72 \mathrm{~m}$, while the values from CLASS simulations range between 1.20 and $1.49 \mathrm{~m}$ (Table 3). Notwithstanding the overestimated observed snowpack at QC-Juv, CLASS simulations produced a similar average length of the snow season ( $\approx 194$ days) and an average length of the snowmelt period ( $\approx 57$ days) estimates compared to observations (Table 3). Furthermore, the CLASS simulations are, in general, able to capture the early stage of the snow accumulation period and the snowpack variations throughout the season caused by snowfall and snowmelt events (Fig. 8a).

Generally, the snowpack simulated by CLASS shows a higher correlation (Pearson correlation, $r$ ) with observations $(r=0.93)$ and a smaller root-mean-square error $(\mathrm{RMSE} \approx 0.12 \mathrm{~m}$ ) at the QC-OBS site compared to the results obtained for the QC-Juv site. Nonetheless, all CLASS runs fail in simulating the average length of the snow season at QC-OBS. On average, the snow period at QC-OBS simulated by CLASS-CTL is 4 days longer than observations, whereas CLASS-RNL prolongs the season by 22 days more on average (Table 3 ). The snowpack at QC-OBS melts in about 47 days at a rate of $8.5 \mathrm{~mm} \mathrm{day}^{-1}$, whereas the simulated snowpack takes up to 75 days to melt entirely at a slower rate of $\approx 9.8 \mathrm{~mm} \mathrm{day}^{-1}$ (Table 3). The late snowmelt simulated by all CLASS models is seen in Fig. 8b. This long simulated snow season is possibly associated with errors in the estimation of the snow density and snow thermal conductivity, which should be further investigated. 



FIG. 8. Time series of observed and simulated daily average snowpack depth at the (a) QC-Juv, (b) QC-OBS, (c) ON-OMW, and (d) SK-OAS sites. Blue, green, and red lines correspond to CTL, RNL, and RNL-ObsP simulations, respectively. Black lines represent the observations.

CLASS performance at the ON-OMW site is similar to that at the QC-OBS site. Statistical scores show that snowpack depth is well simulated by the models that are driven by ERA5 and observed data.

Last, the simulated snowpack depth values are in overall excellent agreement with observations at the driest site (SK-OAS), showing similar maximum values of accumulated snow and snow season duration, with high correlation and Kling-Gupta efficiency (KGE) values $(r \approx 0.88$ and KGE ranging from 0.74 to 0.85 ) and small biases (RMSE $\approx 0.07$ and relative bias ranging from $-15.9 \%$ to $2.3 \%$; Table 3). Additionally, the year-to-year variation in snow cover at this site, which is relatively more significant compared to the more humid sites (QC-Juv, QC-OBS, and ON-OMW), is well captured by CLASS although this site has the smallest amount of accumulated snow. For instance, the maximum value of accumulated snow during the $2002 / 03$ winter was about $0.25 \mathrm{~m}$, while the maximum values were about $0.75 \mathrm{~m}$ during the 2004/05 and 2005/06 winters. However, snowmelt duration in CLASS simulations is slightly longer (up to 7 days) than observations, which, similar to the QC-OBS winters, might be related to errors in the estimation of snow thermal conductivity and snow density. 
TABLE 3. Statistical summary of the comparison between simulated and observed daily mean values of snowpack depth at each study site. The terms $M_{\mathrm{obs}}$ and $M_{\mathrm{sim}}$ are the maximum mean value of accumulated snow from observations and CLASS simulations (CTL, RNL, and RNL-ObsP), respectively; $L_{\mathrm{obs}}$ and $L_{\text {sim }}$ are the average length (in days) of the snow season from observations and CLASS simulations, respectively. $\mathrm{MR}_{\mathrm{obs}}$ and $\mathrm{MR}_{\mathrm{sim}}$ are the average snowmelt ratio computed using the period between the day of maximum accumulated snow from observations and simulations until the end of the snow period; $L_{\mathrm{mr}}$ is the average length of the snowmelt period. The statistical metrics are the RMSE, relative bias, $r$, and KGE.

\begin{tabular}{|c|c|c|c|c|c|c|c|c|c|c|}
\hline $\begin{array}{c}\text { CLASS } \\
\text { simulation }\end{array}$ & $M_{\mathrm{obs}}(\mathrm{m})$ & $M_{\text {sim }}(\mathrm{m})$ & $L_{\text {obs }}$ (days) & $L_{\text {sim }}(\mathrm{d})$ & $\begin{array}{c}\mathrm{MR}_{\mathrm{obs}} \\
\left(\mathrm{mm} \mathrm{day}^{-1}\right) \\
\mid L_{\mathrm{mr}}(\text { days })\end{array}$ & $\begin{array}{c}\mathrm{MR}_{\mathrm{sim}} \\
\left(\mathrm{mm} \mathrm{day}^{-1}\right) \\
\mid L_{\mathrm{mr}} \text { (days) }\end{array}$ & RMSE (m) & Bias (\%) & $r$ & KGE \\
\hline \multicolumn{11}{|c|}{ QC-Juv } \\
\hline CTL & & 1.20 & & 194 & & $18.8 \mid 60$ & 0.56 & -42.5 & 0.85 & 0.39 \\
\hline RNL & 1.72 & 1.49 & 194 & 213 & $23.5 \mid 60$ & $24.6 \mid 62$ & 0.31 & -22.1 & 0.94 & 0.66 \\
\hline RNL-ObsP & & 1.24 & & 189 & & $26.0 \mid 49$ & 0.51 & -38.6 & 0.86 & 0.45 \\
\hline \multicolumn{11}{|c|}{ QC-OBS } \\
\hline CTL & & 0.76 & & 173 & & $8.6 \mid 64$ & 0.13 & -13.2 & 0.93 & 0.72 \\
\hline RNL & 0.92 & 0.87 & 169 & 183 & $8.5 \mid 47$ & $11.5 \mid 69$ & 0.09 & 2.5 & 0.93 & 0.84 \\
\hline RNL-ObsP & & 0.79 & & 172 & & $9.2 \mid 75$ & 0.13 & -16.0 & 0.93 & 0.89 \\
\hline \multicolumn{11}{|c|}{ ON-OMW } \\
\hline CTL & & 0.78 & & 166 & & $13.9 \mid 57$ & 0.09 & 18.8 & 0.94 & 0.80 \\
\hline RNL & 0.68 & 0.59 & 151 & 140 & $13.4 \mid 48$ & $12.0 \mid 49$ & 0.08 & -6.2 & 0.87 & 0.78 \\
\hline RNL-ObsP & & 0.73 & & 148 & & $14.0 \mid 54$ & 0.09 & 10.5 & 0.90 & 0.80 \\
\hline \multicolumn{11}{|c|}{ SK-OAS } \\
\hline CTL & & 0.38 & & 165 & & $6.9 \mid 51$ & 0.08 & -15.9 & 0.88 & 0.74 \\
\hline RNL & 0.46 & 0.41 & 163 & 174 & $6.8 \mid 44$ & $8.7 \mid 42$ & 0.06 & 2.3 & 0.90 & 0.85 \\
\hline RNL-ObsP & & 0.41 & & 173 & & $7.9 \mid 47$ & 0.07 & -4.8 & 0.85 & 0.82 \\
\hline
\end{tabular}

The satisfactory performance of CLASS for the simulation of snow depth in boreal forested environments presented in this study is in agreement with Verseghy et al. (2017), who used the same model version (3.6) to simulate snow over eastern Canada using ERA-Interim for meteorological forcing. They compared the simulated fractional snow cover with satellite observations (NOAA Interactive Multisensor Snow and Ice Mapping System and MODIS, with a spatial resolution of approximately $24 \mathrm{~km}$ ). They concluded that CLASS produced reasonable simulated results for snow properties over this region, though there were issues concerning the estimation of surface albedo and snow water equivalent.

CLASS simulations show some systematic biases during the late-snow season in our study, especially at QCOBS and SK-OAS, and should be carefully considered as a critical error (Figs. $8 \mathrm{~b}$ and $8 \mathrm{~d}$, and Table 3 ). The extended persistent snow cover caused by bias in the simulation of some snowpack properties at these sites seriously affects the simulation of soil temperature and moisture, as presented in section 4e. This suggestion of possible bias for snow simulation is partly refuted in Verseghy et al. (2017). Indeed, they reported that the snow albedo refreshment threshold and snow thermal conductivity formulation in previous versions of CLASS were responsible for the unrealistically long persistence of the snow cover, which was no longer present in model version 3.6.
In general, the discrepancies between simulated and observed snowpack depth at all sites can be attributed to a combination of many factors: (i) errors in the estimation of sublimation losses, (ii) errors in snow depth simulation at a particular time step that can be systematically propagated afterward, (iii) uncertainties in precipitation (snowfall/rainfall) and snow depth measurements, and (iv) errors due to the precipitation partitioning threshold between snow and rain in the model versus observations. This last factor was dismissed as a possible source of bias by Zhang et al. (2008) for the simulation of snowpack depth at SK-OAS. They compared the observations at the SK-OAS site with simulations using another LSM (EALCO model) by studying the partitioning of precipitation between rain and snow using a $0^{\circ} \mathrm{C}$ air temperature threshold as well as a polynomial distribution method for the $0^{\circ}-6^{\circ} \mathrm{C}$ air temperature range proposed by Bartlett et al. (2006). They found that altering the partitioning method could result in snow depth variations of approximately $10 \%$. These results agree with the tests that we performed with CLASS to evaluate the possible impacts of the selected precipitation partitioning method used to simulate snowpack depth. We compared the standard method (snowfall occurring at air temperatures $\leq 0^{\circ} \mathrm{C}$ ) used in CLASS with the Bartlett et al. (2006) method and with a linear interpolation method that partitions the precipitation into snow and rain for air temperature ranging from $0^{\circ}$ to $2^{\circ} \mathrm{C}$. Overall, none of the 
$-\mathrm{CTL}-\mathrm{RNL}-\mathrm{RNL}-\mathrm{ObsP}-\mathrm{OBS}$
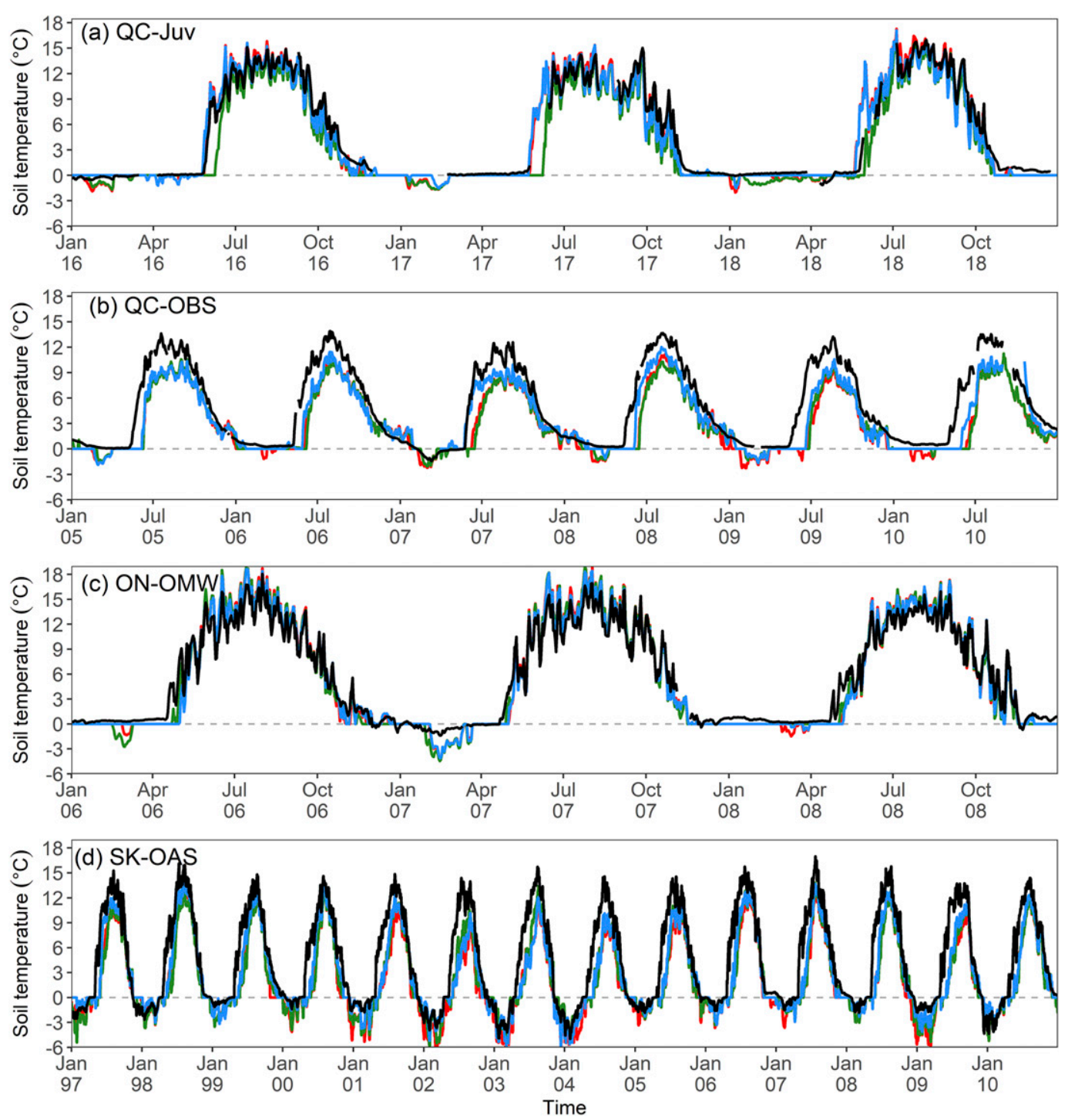

FIG. 9. Time series of observed and simulated daily average soil temperature at the (a) QC-Juv, (b) QC-OBS, (c) ON-OMW, and (d) SK-OAS sites. Blue, green, and red lines correspond to CTL, RNL, and RNL-ObsP simulations, respectively. Black lines represent the in situ observations of soil temperature taken at $0.04 \mathrm{~m}$ deep at QC-Juv, $0.20 \mathrm{~m}$ deep at QC-OBS, $0.05 \mathrm{~m}$ deep at ON-OMW, and $0.10 \mathrm{~m}$ deep at SK-OAS.

methods affect the mid-snow season, but the snowmelt period is affected. With the standard method, CLASS simulates a slightly shorter snowmelt period, which is in better agreement with observations than with the other proposed methods (not shown).

\section{e. Simulation of soil state variables}

Soil temperature and water content are variables that have a significant impact on soil infiltration capacity, evaporation, and respiration. Note that the analyses below concern simulated soil variables for the organic soil layer (0.0-0.1 m deep) at the QC-Juv and ON-OMW sites and the top mineral soil layer (0.1-0.2 $\mathrm{m}$ deep) at the QC-OBS and SK-OAS sites. The in situ observations of soil temperature and soil moisture at each site are representative of the selected simulated soil layers.

The simulated soil temperature values from the three CLASS runs are very similar to each other and are in good overall agreement with the observations, as shown in Fig. 9 and Table 4. Furthermore, the biases in ERA5 precipitation do not show major impacts on soil temperature simulated by CLASS.

The CLASS simulations for the QC-Juv (Fig. 9a) and ON-OMW sites (Fig. 9c) show slightly better performance 
TABLE 4. Statistical summary of the comparison between simulated and observed daily mean values of soil temperature. The statistical metrics are the RMSE, relative bias, $r$, and KGE.

\begin{tabular}{|c|c|c|c|c|}
\hline $\begin{array}{l}\text { CLASS } \\
\text { simulation }\end{array}$ & RMSE $\left({ }^{\circ} \mathrm{C}\right)$ & Bias (\%) & $r$ & KGE \\
\hline \multicolumn{5}{|c|}{ QC-Juv } \\
\hline CTL & 1.10 & -6.4 & 0.98 & 0.93 \\
\hline RNL & 1.49 & -20.0 & 0.98 & 0.79 \\
\hline RNL-ObsP & 1.07 & -5.6 & 0.98 & 0.93 \\
\hline \multicolumn{5}{|c|}{ QC-OBS } \\
\hline CTL & 2.16 & -29.7 & 0.95 & 0.65 \\
\hline RNL & 2.76 & -39.1 & 0.91 & 0.54 \\
\hline RNL-ObsP & 2.70 & -40.2 & 0.92 & 0.54 \\
\hline \multicolumn{5}{|c|}{ ON-OMW } \\
\hline CTL & 1.18 & -2.3 & 0.99 & 0.88 \\
\hline RNL & 1.25 & -1.7 & 0.99 & 0.85 \\
\hline RNL-ObsP & 1.31 & -0.7 & 0.99 & 0.84 \\
\hline \multicolumn{5}{|c|}{ SK-OAS } \\
\hline CTL & 2.63 & -36.5 & 0.94 & 0.60 \\
\hline RNL & 3.00 & -46.6 & 0.93 & 0.50 \\
\hline RNL-ObsP & 3.20 & -53.1 & 0.93 & 0.44 \\
\hline
\end{tabular}

than for the QC-OBS (Fig. 9b) and SK-OAS sites (Fig. 9d), with greater $\mathrm{KGE}$ values $(>0.79)$ and smaller values of RMSE and relative bias (Table 4). Indeed, all CLASS simulations underestimate the average soil temperature at the QC-OBS and SK-OAS sites by approximately $2.5^{\circ} \mathrm{C}$ (bias $\approx-36 \%$ ) and $2.9^{\circ} \mathrm{C}$ (bias $\approx-45 \%$ ), respectively.

The underestimation of soil temperature values by all CLASS simulations occurs during the late snowmelt period and the growing season at the QC-OBS because of a lengthy simulated snow season (as previously discussed in section 4e), which prevents the soil from heating up and consequently propagates this temperature trend (colder soil temperature) over time.

The soil temperature underestimation occurs during the snow accumulation period at SK-OAS. It is possibly linked to an overestimation of snow thermal conductivity. We performed tests that demonstrate that decreasing snow thermal conductivity in CLASS by $40 \%$ would produce a better agreement between the simulated and observed soil temperature at this site and have a smaller bias (bias $\approx-15 \%$ and $\mathrm{RMSE} \approx 2.0^{\circ} \mathrm{C}$ ) and KGE (0.8) (not shown). Despite the notable discrepancies in the comparison between observed and simulated soil temperatures during winter at this site, it is important to highlight the ability of observation and ERA5 reanalysis driven CLASS to capture the negative soil temperatures during this period.

Overall, soil temperature patterns are well captured by all CLASS simulations for all sites. For example, CLASS is able to reproduce the fact that the soils at the
QC-Juv, QC-OBS, and ON-OMW sites are not frozen most of the time during the snow period, with temperatures hovering around $0^{\circ} \mathrm{C}$. Temperature swings are well replicated by CLASS during the growing season (from June to September) at the QC-Juv and ON-OMW sites. These examples highlight the model's ability to simulate the soil thermal regime of boreal forests, although the soil composition is characterized by high spatial variability, which makes it challenging to perform a fair comparison between simulations and observations (Zhuang et al. 2001; Bond-Lamberty et al. 2005; Khomik et al. 2006). For instance, Bond-Lamberty et al. (2005) investigated the small-scale spatiotemporal variability of the soil temperature at a Canadian boreal forest and reported a consistent high spatial variability in shallower soil layers compared to deeper ones, especially for distances longer than $5 \mathrm{~m}$.

Figure 10 shows the temporal evolution of soil moisture over a multiyear period at the study sites. In general, CLASS driven by ERA5 reanalysis agrees very well with the control simulation (CTL) for simulating soil moisture at all sites, with no significant impact from bias in ERA5 precipitation. However, the simulations show that seasonal and year-to-year variations of the soil moisture are well captured by CLASS only at the QCJuv and QC-OBS sites (Figs. 10a,b).

The soil moisture simulations at ON-OMW (Fig. 10c) show reasonable agreement with observations for only some parts of the snow accumulation period (DJFM) and late snowmelt period (May). For the most part, however, CLASS results greatly disagree with observations, showing many oscillations (peaks) that are not shown by the measurements. Its high spatial variability could explain the discrepancies found between simulated and observed soil moisture at this mixed forest composed of deciduous and evergreen trees, which CLASS was not able to capture.

Soil moisture is quite well simulated during the snowmelt and growing periods (AM and JJAS) at the SK-OAS (Fig. 10d) site when the soil has a higher water availability following snowmelt and rainfall events (see Fig. 10d). However, CLASS results consistently deviate from observations during the snow accumulation period (from December to March) when measured values of soil moisture show liquid water in the frozen soil while the model does not allow for the existence of liquid water in soil when the temperature is below $0^{\circ} \mathrm{C}$. The observed soil moisture during the cold period at this site ranges mostly between 0.1 and $0.2 \mathrm{~m}^{3} \mathrm{~m}^{-3}$, while the simulated values are set to a minimum threshold of $0.04 \mathrm{~m}^{3} \mathrm{~m}^{-3}$, assuming, therefore, the absence of unfrozen water in the soil. However, according to the metadata documentation of the SK-OAS site, the data quality of the soil moisture is quite unreliable when the soil is frozen, and they are therefore not very useful during winter. 

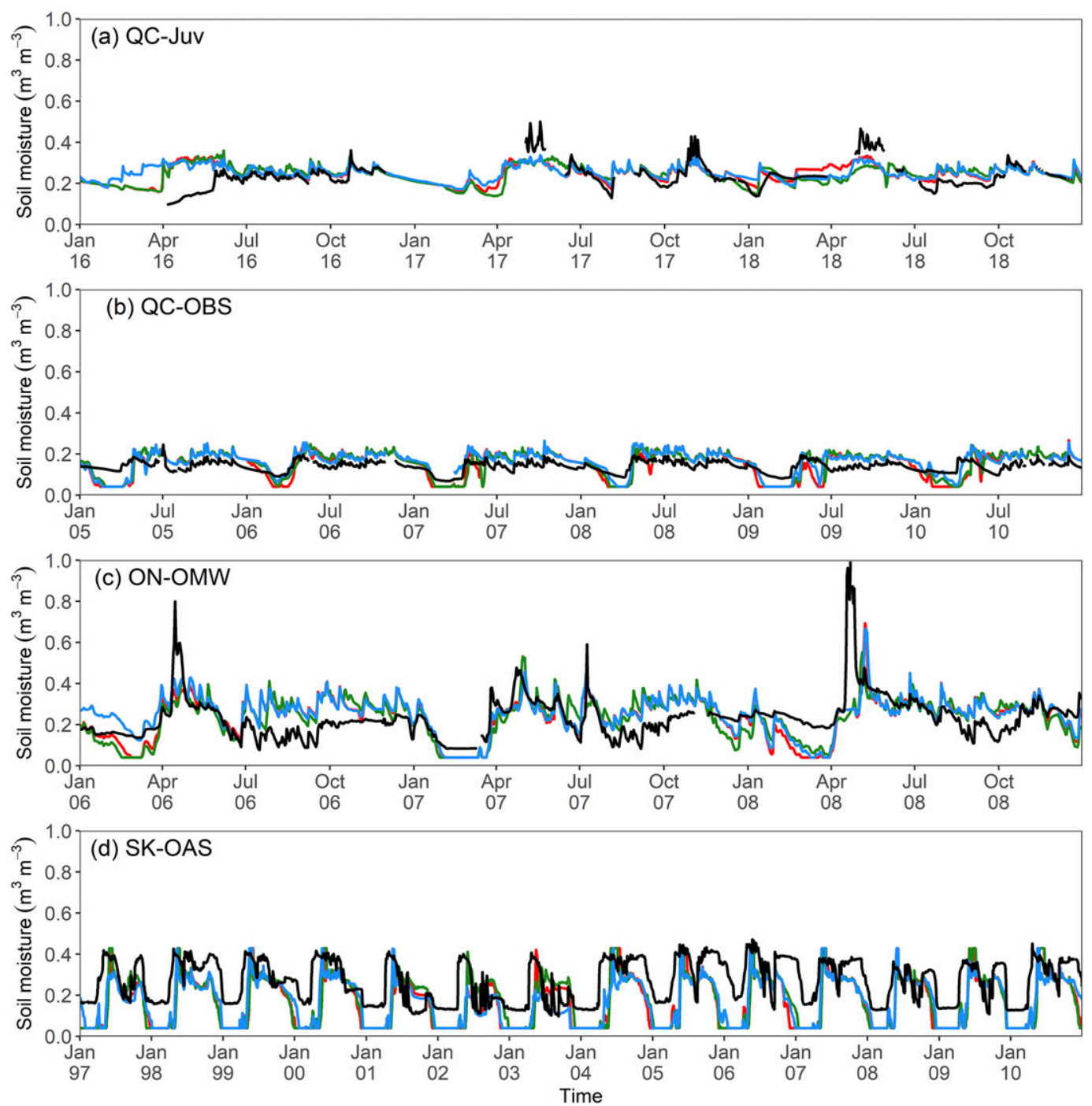

FIG. 10. Time series of observed and simulated daily average soil moisture at the (a) QC-Juv, (b) QC-OBS, (c) ON-OMW, and (d) SK-OAS sites. Observed soil moisture (black line) represents the moisture availability in the topsoil layer (within $\sim 0.15 \mathrm{~m}$ deep from the skin soil surface). Blue, green, and red lines correspond to CTL, RNL, and RNL-ObsP simulations, respectively.

Some studies have proven the importance of accounting for the existence of liquid water in simulated frozen soils for the simulation of surface energy balance and soil temperature ( $\mathrm{Li}$ and Koike 2003; Luo et al. 2003; Ling and Zhang 2004). Ganji et al. (2017) have proposed the improvement of how frozen water is treated in CLASS by modifying the soil hydraulic conductivity and potential matric formulations. Their results suggested a considerable decrease of simulated water infiltration into the soil and, therefore, soil moisture during the snowmelt period, which were in better agreement with observations. The modification proposed by Ganji et al. (2017) was not officially implemented in the model and, therefore, not used in our simulations.

Figure 11 presents the CLASS's ability to simulate soil moisture over a mean intra-annual variation with monthly mean values and reinforces the results discussed in Fig. 10. Overall, statistical metrics, such as unbiased RMSE (ubRMSE), relative bias, and $r$, show good performance for all CLASS simulations (CTL, RNL, and RNL-ObsP) compared to observations, as presented in Table 5. On average, the comparison between simulations and observations shows higher correlations and smaller errors at the QC-Juv $(r \approx 0.73$, ubRMSE $\approx 0.041 \mathrm{~m}^{3} \mathrm{~m}^{-3}$, relative bias $\left.\approx 2.2 \%\right)$ and 

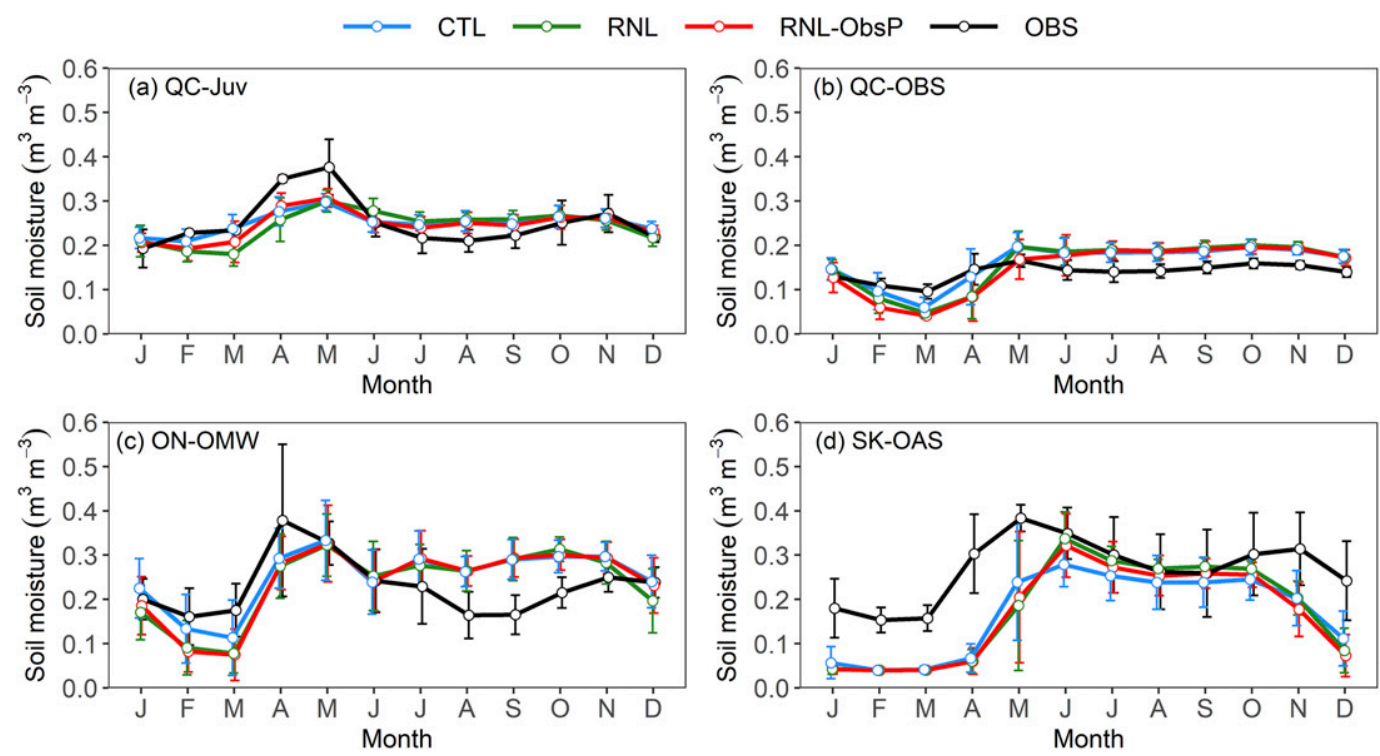

FIG. 11. Mean intra-annual variation of observed and simulated monthly average values of soil moisture at the (a) QC-Juv, (b) QC-OBS, (c) ON-OMW, and (d) SK-OAS sites. Observed soil moisture (black line) represents the water availability in the topsoil layer (within $0 \mathrm{~m}$ and $\sim 0.15 \mathrm{~m}$ deep from the soil surface). Blue, green, and red lines correspond to CTL, RNL, and RNL-ObsP simulations, respectively. Vertical error bars from observations and simulations correspond to standard deviation values for each month.

QC-OBS $\left(r \approx 0.85\right.$, ubRMSE $\approx 0.036 \mathrm{~m}^{3} \mathrm{~m}^{-3}$, bias $\approx 11.3 \%)$ sites compared to the ON-OMW $(r \approx 0.51$, ubRMSE $\approx 0.073 \mathrm{~m}^{3} \mathrm{~m}^{-3}$, bias $\left.\approx 5.6 \%\right)$ and SK-OAS $\left(r \approx 0.71\right.$, ubRMSE $\approx 0.074 \mathrm{~m}^{3} \mathrm{~m}^{-3}$, bias $\left.\approx-36 \%\right)$ sites.

First, CLASS shows a slight underestimation of soil moisture during snowmelt (April-May) at the QC-Juv (Fig. 11a) site, which may be due to the lateral movement (interflow) of soil water that occurs on the site but is not taken into account in the (1D) model, as previously discussed in section $4 \mathrm{c}$. The underestimation of soil moisture during the mid- to late snow period (from February to April) at QC-OBS (Fig. 11b) was caused by periods (e.g., February 2005 and 2009) when simulated soil temperature was also underestimated thereby producing negative temperatures (see Fig. 9d), which set the simulated soil moisture to $0.04 \mathrm{~m}^{3} \mathrm{~m}^{-3}$. The monthly mean of simulated soil moisture values at the ON-OMW (Fig. 11c) site does not represent the poor results highlighted in Fig. 10c; instead, the comparison between simulated and observed monthly values are relatively good from November to June and greatly overestimated from July to October (warmer period). Last, CLASS simulations for SK-OAS (Fig. 11d) show good results for soil moisture from June to October (snow-free season) but fail during the snow period, as previously mentioned for Fig. 10d.

\section{Conclusions}

The performance of the ERA5 reanalysis driving the Canadian Land Surface Scheme (CLASS-RNL) over
Canadian boreal forests was assessed in this study. The analyses were focused on the evaluation of simulated surface energy fluxes (net radiation, sensible heat, and latent heat), and other variables linked to the surface water and energy balance such as evapotranspiration, total runoff, snowpack, and soil temperature and moisture. To this end, we compared the results from CLASS-RNL with observations and with the results from CLASS driven

TABLE 5. Statistical summary of the comparison between simulated and observed monthly mean values of soil moisture. The statistical metrics are the ubRMSE, relative bias, and $r$.

\begin{tabular}{lccc}
\hline \hline $\begin{array}{c}\text { CLASS } \\
\text { simulation }\end{array}$ & $\begin{array}{l}\text { ubRMSE } \\
\left(\mathrm{m}^{3} \mathrm{~m}^{-3}\right)\end{array}$ & $\begin{array}{c}\text { Bias } \\
(\%)\end{array}$ & $r$ \\
\hline \multicolumn{4}{c}{ QC-Juv } \\
CTL & 0.039 & -0.6 & 0.82 \\
RNL & 0.048 & -3.3 & 0.55 \\
RNL-ObsP & 0.035 & -2.6 & 0.81 \\
& QC-OBS & & \\
CTL & 0.027 & 15.1 & 0.91 \\
RNL & 0.040 & 12.3 & 0.82 \\
RNL-ObsP & 0.041 & 6.6 & 0.81 \\
& ON-OMW & & \\
CTL & 0.064 & 9.8 & 0.55 \\
RNL & 0.078 & 2.5 & 0.48 \\
RNL-ObsP & 0.076 & 4.5 & 0.51 \\
& & & \\
CTL & SK-OAS & -37.2 & 0.77 \\
RNL & 0.060 & -34.6 & 0.67 \\
RNL-ObsP & 0.085 & -37.6 & 0.70 \\
\hline
\end{tabular}


by observations (CLASS-CTL). We also investigated the impacts of a possible bias in the ERA5 precipitation data on the variables of interest by driving CLASS with ERA5 and observed precipitation (CLASS-RNL-ObsP). Our goal was to evaluate whether CLASS driven by the ERA5 data at the selected boreal sites can produce results comparable to the observations and the CLASS-CTL.

The probability distribution of the simulated surface energy fluxes at the investigated sites and their mean seasonal variations were compared with observations. The results showed that outputs from CLASS-RNL generally compare well with both CLASS-CTL and observations, though there were notable discrepancies between simulated and observed heat fluxes at the 30-min temporal scale. The CLASS-RNL-ObsP results compared to CLASS-RNL and CLASS-CTL showed that the surface heat fluxes, particularly the latent heat flux, are more likely to be affected by biases in the ERA5 precipitation data. More substantial discrepancies between LE simulated by CLASS-RNL-ObsP and CLASS-RNL occur at periods when observed LE values are above $\approx 400 \mathrm{~W} \mathrm{~m}^{-2}$, which mostly take place during the growing season.

The sensitivity analysis of the water balance components showed that CLASS-RNL well reproduced the partitioning of precipitation between evapotranspiration and runoff simulated by CLASS-CTL. About $70 \%$ of precipitation at the most humid boreal sites (QC-Juv and QC-OBS) was converted into the runoff, while this amount was reduced to about $40 \%-50 \%$ at the drier sites (ON-OMW and SKOAS). The input water surplus impacted the simulated total runoff and evapotranspiration, particularly at the most humid sites where ERA5 overestimated the precipitation. It must be highlighted, however, that the absence of in situ measurements of runoff prevented the validation of the simulation results of this variable.

The temporal variation of the snowpack depth was quite well captured by CLASS, but it persisted for too long, especially at QC-OBS and ON-OMW, which is possibly associated with an overestimation of snow thermal conductivity or snow density. Overall, the snowpack data simulated by CLASS-RNL showed a good statistical agreement with both the CLASS-CTL and the observation data. Nonetheless, the overestimated precipitation in ERA5 data slightly affected the simulated snowpack depth, particularly at the humid sites (QCJuv and QC-OBS), where the precipitation bias is relatively high.

CLASS-RNL is very good at capturing soil conditions, and the biases in ERA5 precipitation did not significantly affect the simulated variables. The simulated soil temperatures were, in general, quite similar to observations. In general, patterns of variation for soil temperature were well captured by CLASS. For instance, it allowed the soil to freeze at SK-OAS but not at the other sites. Soil moisture simulations by CLASSRNL and CLASS-CTL were quite comparable. Overall, the simulated values of soil moisture were in better agreement with observations at QC-Juv and QC-OBS than at ON-OMW and SK-OAS. The high spatial variability of soil moisture and the lower reliability of its measurement have certainly contributed to the reported discrepancies.

In conclusion, this study highlights the ability of CLASS to represent the land surface variables of the boreal sites when forced by the ERA5 reanalysis, showing high similarity with the observations and with the results from the CLASS-CTL simulation. In general, positive biases in ERA5 precipitation showed to produce overestimations in the simulated surface heat fluxes, water balance components, and snowpack depth. This issue may be circumvented, in some cases, by substituting ERA5 precipitation with observed precipitation.

Additionally, the results found to bring some future work perspectives regarding the use of ERA5 reanalysis to drive LSMs in local-scale studies of the boreal forest. The reanalysis data offer a much longer and consistent time series than usually found in local observations. Although the ERA5 reanalysis has a relatively coarse resolution $(31 \mathrm{~km} \times 31 \mathrm{~km})$ and vertical adjustment may be required for some forcing variables (e.g., air temperature and specific humidity), the data can still be used to drive an LSM and produce satisfactory results at a local scale. This reanalysis data allows performing the hydrometeorological studies over extended periods and regions where observations are not available. For instance, offline simulations of sophisticated LSMs, such as CLASS, may be beneficial to reexamine some extreme events of the past decades, such as droughts and floods, to better understand the driving mechanisms.

Future studies should consider investigating the impacts on the simulation of surface variables caused by biases in ERA5 variables other than precipitation. Also, further investigations should focus on evaluating simulated runoff from CLASS driven by ERA5 using in situ observations at various boreal sites.

Acknowledgments. We acknowledge the financial support of the Ouranos Consortium on regional climatology and adaptation to climate change, HydroQuébec, the Natural Sciences and Engineering Research Council of Canada, the MELCC, and Environment and Climate Change Canada through project RDC-47712514 entitled "Modélisation hydrologique avec bilan énergétique (ÉVAP)." This work used surface measurements acquired by the ÉVAP Project and by the 
FLUXNET Canada Research Network-Canadian Carbon Program Data Collection (https://daac.ornl.gov/FLUXNET/ guides/FLUXNET_Canada.html). The ERA5 reanalysis data are provided by Copernicus Climate Change Service.

\section{REFERENCES}

Abramowitz, G., R. Leuning, M. Clark, and A. Pitman, 2008: Evaluating the performance of land surface models. J. Climate, 21, 5468-5481, https://doi.org/10.1175/2008JCLI2378.1.

Adler, R. F., and Coauthors, 2003: The version-2 Global Precipitation Climatology Project (GPCP) monthly precipitation analysis (1979-present). J. Hydrometeor., 4, 1147-1167, https://doi.org/ 10.1175/1525-7541(2003)004<1147:TVGPCP > 2.0.CO;2.

Aguado, E., 1985: Radiation balances of melting snow covers at an open site in the central Sierra Nevada, California. Water Resour. Res., 21, 1649-1654, https://doi.org/10.1029/ WR021i011p01649.

Albergel, C., E. Dutra, S. Munier, J. C. Calvet, J. Munoz-Sabater, P. De Rosnay, and G. Balsamo, 2018: ERA-5 and ERAInterim driven ISBA land surface model simulations: Which one performs better? Hydrol. Earth Syst. Sci., 22, 3515-3532, https://doi.org/10.5194/hess-22-3515-2018.

Alves, M., B. Music, D. F. Nadeau, and F. Anctil, 2019: Comparing the performance of the Maximum Entropy Production model with a land surface scheme in simulating surface energy fluxes. J. Geophys. Res. Atmos., 124, 3279-3300, https://doi.org/ 10.1029/2018JD029282.

Anderson, R. G., and D. Wang, 2014: Energy budget closure observed in paired Eddy Covariance towers with increased and continuous daily turbulence. Agric. For. Meteor., 184, 204-209, https://doi.org/10.1016/j.agrformet.2013.09.012.

Arain, M. A., T. A. Black, A. G. Barr, P. G. Jarvis, J. M. Massheder, D. L. Verseghy, and Z. Nesic, 2002: Effects of seasonal and interannual climate variability on net ecosystem productivity of boreal deciduous and conifer forests. Can. J. For. Res., 32, 878-891, https://doi.org/10.1139/x01-228.

Arora, V. K., and G. J. Boer, 2002: A GCM-based assessment of the global moisture budget and the role of land-surface moisture reservoirs in processing precipitation. Climate Dyn., 20, 13-29, https://doi.org/10.1007/s00382-002-0274-4.

Balsamo, G., A. Beljaars, K. Scipal, P. Viterbo, B. van den Hurk, M. Hirschi, and A. K. Betts, 2009: A revised hydrology for the ECMWF model: Verification from field site to terrestrial water storage and impact in the Integrated Forecast System. J. Hydrometeor., 10, 623-643, https://doi.org/10.1175/ 2008JHM1068.1.

Bartlett, P. A., J. H. McCaughey, P. M. Lafleur, and D. L. Verseghy, 2000: Performance of the Canadian Land Surface Scheme at temperate aspen-birch and mixed forests, and a boreal young jack pine forest: Tests involving canopy conductance parametrizations. Atmos.-Ocean, 38, 113-140, https:// doi.org/10.1080/07055900.2000.9649642.

, M. D. MacKay, and D. L. Verseghy, 2006: Modified snow algorithms in the Canadian Land Surface Scheme: Model runs and sensitivity analysis at three boreal forest stands. Atmos.Ocean, 44, 207-222, https://doi.org/10.3137/ao.440301.

Bergeron, O., H. A. Margolis, T. A. Black, C. Coursolle, A. L. Dunn, A. G. Barr, and S. C. Wofsy, 2007: Comparison of carbon dioxide fluxes over three boreal black spruce forests in Canada. Global Change Biol., 13, 89-107, https://doi.org/ 10.1111/j.1365-2486.2006.01281.x.
Boisvert, L. N., M. A. Webster, A. A. Petty, T. Markus, D. H. Bromwich, and R. I. Cullather, 2018: Intercomparison of precipitation estimates over the Arctic Ocean and its peripheral seas from reanalyses. J. Climate, 31, 8441-8462, https:// doi.org/10.1175/JCLI-D-18-0125.1.

Bonan, G. B., 2008: Forests and climate change: Forcings, feedbacks, and the climate benefits of forests. Science, 320, 1444-1449, https://doi.org/10.1126/science.1155121.

Bond-Lamberty, B., C. Wang, and S. T. Gower, 2005: Spatiotemporal measurement and modeling of stand-level boreal forest soil temperatures. Agric. For. Meteor., 131, 27-40, https://doi.org/ 10.1016/j.agrformet.2005.04.008.

Bowling, L. C., and Coauthors, 2003: Simulation of high-latitude hydrological processes in the Torne-Kalix basin: PILPS phase 2(e) 1: Experiment description and summary intercomparisons. Global Planet. Change, 38, 1-30, https://doi.org/10.1016/ S0921-8181(03)00003-1.

Brown, R., P. Bartlett, M. MacKay, and D. Verseghy, 2006: Evaluation of snow cover in CLASS for SnowMIP. Atmos.Ocean, 44, 223-238, https://doi.org/10.3137/ao.440302.

Cao, Z., and D.-L. Zhang, 2016: Analysis of missed summer severe rainfall forecasts. Wea. Forecasting, 31, 433-450, https:// doi.org/10.1175/WAF-D-15-0119.1.

Chen, J. M., A. Govind, O. Sonnentag, Y. Zhang, A. Barr, and B. Amiro, 2006: Leaf area index measurements at FLUXNETCanada forest sites. Agric. For. Meteor., 140, 257-268, https:// doi.org/10.1016/j.agrformet.2006.08.005.

Comer, N. T., P. M. Lafleur, N. T. Roulet, M. G. Letts, M. Skarupa, and D. Verseghy, 2000: A test of the Canadian Land Surface Scheme (CLASS) for a variety of wetland types. Atmos.-Ocean, 38, 161-179, https://doi.org/10.1080/ 07055900.2000 .9649644$.

Cosgrove, B. A., and Coauthors, 2003: Real-time and retrospective forcing in the North American Land Data Assimilation System (NLDAS) project. J. Geophys. Res., 108, 8842, https:// doi.org/10.1029/2002JD003118.

Cox, P. M., R. A. Betts, C. D. Jones, S. A. Spall, and I. J. Totterdell, 2000: Acceleration of global warming due to carbon-cycle feedbacks in a coupled climate model. Nature, 408, 184-187, https://doi.org/10.1038/35041539.

Dee, D. P., and Coauthors, 2011: The ERA-Interim reanalysis: Configuration and performance of the data assimilation system. Quart. J. Roy. Meteor. Soc., 137, 553-597, https://doi.org/ 10.1002/qj.828.

—, M. Balmaseda, G. Balsamo, R. Engelen, A. J. Simmons, and J. N. Thépaut, 2014: Toward a consistent reanalysis of the climate system. Bull. Amer. Meteor. Soc., 95, 1235-1248, https://doi.org/10.1175/BAMS-D-13-00043.1.

Dirmhirn, I., and F. D. Eaton, 1975: Some characteristics of the albedo of snow. J. Appl. Meteor., 14, 375-379, https://doi.org/ 10.1175/1520-0450(1975)014<0375:SCOTAO > 2.0.CO;2.

FLUXNET Canada Team, 2016: FLUXNET Canada Research Network - Canadian Carbon Program Data Collection, 19932014. ORNL DAAC, accessed 10 May 2019, https://doi.org/ 10.3334/ornldaac/1335.

Ganji, A., L. Sushama, D. Verseghy, and R. Harvey, 2017: On improving cold region hydrological processes in the Canadian Land Surface Scheme. Theor. Appl. Climatol., 127, 45-59, https://doi.org/10.1007/s00704-015-1618-4.

Hadiwijaya, B., S. Pepin, P.-E. Isabelle, and D. F. Nadeau, 2020: The dynamics of transpiration to evapotranspiration ratio under wet and dry canopy conditions in a humid boreal forest. Forests, 11, 237, https://doi.org/10.3390/F11020237. 
Hedstrom, N. R., and J. W. Pomeroy, 1998: Measurements and modelling of snow interception in the boreal forest. Hydrol. Processes, 12, 1611-1625, https://doi.org/10.1002/(SICI)10991085(199808/09)12:10/11<1611::AID-HYP684>3.0.CO;2-4.

Hersbach, H., and Coauthors, 2018: Operational global reanalysis: Progress, future directions and synergies with NWP including updates on the ERA5 production status. ERA Rep. Series 27, 63 pp., https://www.ecmwf.int/node/18765.

Isabelle, P.-E., D. F. Nadeau, M. H. Asselin, R. Harvey, K. N. Musselman, A. N. Rousseau, and F. Anctil, 2018: Solar radiation transmittance of a boreal balsam fir canopy: Spatiotemporal variability and impacts on growing season hydrology. Agric. For. Meteor., 263, 1-14, https://doi.org/ 10.1016/j.agrformet.2018.07.022.

Jiang, H., Y. Yang, Y. Bai, and H. Wang, 2020: Evaluation of the total, direct, and diffuse solar radiations from the ERA5 reanalysis data in China. IEEE Geosci. Remote Sens. Lett., 17, 47-51, https://doi.org/10.1109/LGRS.2019.2916410.

Jost, G., M. Weiler, D. R. Gluns, and Y. Alila, 2007: The influence of forest and topography on snow accumulation and melt at the watershed-scale. J. Hydrol., 347, 101-115, https://doi.org/ 10.1016/j.jhydrol.2007.09.006.

Khomik, M., M. A. Arain, and J. H. McCaughey, 2006: Temporal and spatial variability of soil respiration in a boreal mixedwood forest. Agric. For. Meteor., 140, 244-256, https://doi.org/ 10.1016/j.agrformet.2006.08.006.

Lafleur, P. M., M. R. Skarupa, and D. L. Verseghy, 2000: Validation of the Canadian Land Surface Scheme (CLASS) for a subarctic open woodland. Atmos.-Ocean, 38, 205-225, https://doi.org/10.1080/07055900.2000.9649646.

Laprise, R., L. Hernández-Díaz, T. Kossivi, L. Sushama, L. Separovic, A. Martynov, K. Winger, and M. Valin, 2013: Climate projections over CORDEX Africa domain using the fifth-generation Canadian Regional Climate Model (CRCM5). Climate Dyn., 41, 3219-3246, https://doi.org/10.1007/s00382-012-1651-2.

Letts, M. G., N. T. Roulet, N. T. Comer, M. R. Skarupa, and D. L. Verseghy, 2000: Parametrization of peatland hydraulic properties for the Canadian land surface scheme. Atmos.-Ocean, 38, 141-160, https://doi.org/10.1080/07055900.2000.9649643.

Li, X., and T. Koike, 2003: Frozen soil parameterization in SiB2 and its validation with GAME-Tibet observations. Cold Reg. Sci. Technol., 36, 165-182, https://doi.org/10.1016/S0165232X(03)00009-0.

Ling, F., and T. Zhang, 2004: A numerical model for surface energy balance and thermal regime of the active layer and permafrost containing unfrozen water. Cold Reg. Sci. Technol., 38, 1-15, https://doi.org/10.1016/S0165-232X(03)00057-0.

Longley, R. W., 1960: Snow depth and snow density at Resolute, Northwest Territories. J. Glaciol., 3, 733-738, https://doi.org/ 10.1017/S0022143000018037.

Luo, L., and Coauthors, 2003: Effects of frozen soil on soil temperature, spring infiltration, and runoff: Results from the PILPS 2(d) experiment at Valdai, Russia. J. Hydrometeor., 4, 334-351, https://doi.org/10.1175/1525-7541(2003)4<334: EOFSOS $>2.0 . \mathrm{CO} ; 2$.

L'vovich, M. I., 1979: World Water Resources and Their Future. Amer. Geophys. Union, 415 pp., http://doi.wiley.com/10.1029/SP013.

Martynov, A., R. Laprise, L. Sushama, K. Winger, L. Šeparović, and B. Dugas, 2013: Reanalysis-driven climate simulation over CORDEX North America domain using the Canadian Regional Climate Model, version 5: Model performance evaluation. Climate Dyn., 41, 2973-3005, https://doi.org/10.1007/s00382013-1778-9.
McCaughey, J. H., M. R. Pejam, M. A. Arain, and D. A. Cameron, 2006: Carbon dioxide and energy fluxes from a boreal mixedwood forest ecosystem in Ontario, Canada. Agric. For. Meteor., 140, 79-96, https://doi.org/10.1016/j.agrformet.2006.08.010.

Metcalfe, R. A., and J. M. Buttle, 1998: A statistical model of spatially distributed snowmelt rates in a boreal forest basin. Hydrol. Processes, 12, 1701-1722, https://doi.org/10.1002/(SICI)10991085(199808/09)12:10/11<1701::AID-HYP690>3.0.CO;2-D.

Music, B., and D. Caya, 2007: Evaluation of the hydrological cycle over the Mississippi river basin as simulated by the Canadian Regional Climate Model (CRCM). J. Hydrometeor., 8, 969988, https://doi.org/10.1175/JHM627.1.

Nordbo, A., L. Järvi, and T. Vesala, 2012: Revised eddy covariance flux calculation methodologies - Effect on urban energy balance. Tellus, 64B, 18184, https://doi.org/10.3402/ tellusb.v64i0.18184.

Pomeroy, J. W., and D. M. Gray, 1995: Snowcover accumulation, relocation and management. National Hydrology Research Institute Science Rep. 7, 144 pp.

Prein, A. F., C. Liu, K. Ikeda, R. Bullock, R. M. Rasmussen, G. J. Holland, and M. Clark, 2017: Simulating North American mesoscale convective systems with a convection-permitting climate model. Climate Dyn., https://doi.org/10.1007/S00382017-3993-2.

Purdy, A. J., J. B. Fisher, M. L. Goulden, and J. S. Famiglietti, 2016: Ground heat flux: An analytical review of 6 models evaluated at 88 sites and globally. J. Geophys. Res. Biogeosci., 121, 30453059, https://doi.org/10.1002/2016JG003591.

Robinson, D. A., and G. Kukla, 1984: Albedo of a dissipating snow cover. J. Climate Appl. Meteor., 23, 1626-1634, https://doi.org/ 10.1175/1520-0450(1984)023<1626:AOADSC > 2.0.CO;2.

Rustemeier, E., M. Ziese, A. Meyer-Christoffer, U. Schneider, P. Finger, and A. Becker, 2019: Uncertainty assessment of the ERA-20C reanalysis based on the monthly in situ precipitation analysis of the Global Precipitation Climatology Centre. J. Hydrometeor., 20, 231-250, https://doi.org/10.1175/JHM-D17-0239.1.

Rutter, N., and Coauthors, 2009: Evaluation of forest snow processes models (SnowMIP2). J. Geophys. Res., 114, D06111, https://doi.org/10.1029/2008JD011063.

Schlesinger, W. H., 1991: Biogeochemistry: An Analysis of Global Change. Academic Press, 443 pp.

Schlosser, C. A., A. G. Slater, A. Robock, A. J. Pitman, K. Y. Vinnikov, A. Henderson-Sellers, N. A. Speranskaya, and K. Mitchell, 2000: Simulations of a boreal grassland hydrology at Valdai, Russia: PILPS Phase 2(d). Mon. Wea. Rev., 128, 301-321, https://doi.org/10.1175/1520-0493(2000)128<0301: $\mathrm{SOABGH}>2.0 . \mathrm{CO} ; 2$.

Sellers, P. J., and Coauthors, 1997: Modeling the exchanges of energy, water, and carbon between continents and the atmosphere. Science, 275, 502-509, https://doi.org/10.1126/ science.275.5299.502.

Šeparović, L., A. Alexandru, R. Laprise, A. Martynov, L. Sushama, K. Winger, K. Tete, and M. Valin, 2013: Present climate and climate change over North America as simulated by the fifthgeneration Canadian regional climate model. Climate Dyn., 41, 3167-3201, https://doi.org/10.1007/s00382-013-1737-5.

Simmons, A. J., K. M. Willett, P. D. Jones, P. W. Thorne, and D. P. Dee, 2010: Low-frequency variations in surface atmospheric humidity, temperature, and precipitation: Inferences from reanalyses and monthly gridded observational data sets. J. Geophys. Res., 115, D01110, https://doi.org/10.1029/ 2009JD012442. 
Slater, A. G., and Coauthors, 2001: The representation of snow in land surface schemes: Results from PILPS 2(d). J. Hydrometeor., 2, 7-25, https://doi.org/10.1175/15257541(2001)002<0007:TROSIL > 2.0.CO;2.

Steele, S. J., S. T. Gower, J. G. Vogel, and J. M. Norman, 1997: Root mass, net primary production and turnover in aspen, jack pine and black spruce forests in Saskatchewan and Manitoba, Canada. Tree Physiol., 17, 577-587, https://doi.org/10.1093/ treephys/17.8-9.577.

Stocks, B. J., and Coauthors, 1998: Climate change and forest fire potential in Russian and Canadian Boreal forests. Climatic Change, 38, 1-13, https://doi.org/10.1023/A:1005306001055.

Sturm, M., J. Holmgren, M. König, and K. Morris, 1997: The thermal conductivity of seasonal snow. J. Glaciol., 43, 26-41, https://doi.org/10.1017/S0022143000002781.

Tarek, M., F. P. Brissette, and R. Arsenault, 2020: Evaluation of the ERA5 reanalysis as a potential reference dataset for hydrological modelling over North America. Hydrol. Earth Syst. Sci., 24, 2527-2544, https://doi.org/10.5194/hess-242527-2020.

Urraca, R., T. Huld, A. Gracia-Amillo, F. J. Martinez-de-Pison, F. Kaspar, and A. Sanz-Garcia, 2018: Evaluation of global horizontal irradiance estimates from ERA5 and COSMO-REA6 reanalyses using ground and satellite-based data. Sol. Energy, 164, 339-354, https://doi.org/10.1016/j.solener.2018.02.059.

Verseghy, D. L., 1991: Canadian Land Surface Scheme for GCMS I. Soil model. Int. J. Climatol., 11, 111-133, https://doi.org/ 10.1002/joc.3370110202.

- 2012: CLASS - The Canadian Land Surface Scheme (version 3.6). Tech. Doc., 179 pp., https://wiki.usask.ca/download/ attachments/223019286/CLASS_v3.6_Documentation.pdf? version $=1 \&$ modificationDate $=1478106693000 \&$ api $=v 2$.

_ N. N. A. McFarlane, and M. Lazare, 1993: CLASS - A Canadian land surface scheme for GCMS. II. Vegetation model and coupled runs. Int. J. Climatol., 13, 347-370, https://doi.org/ 10.1002/joc.3370130402.

_- R. Brown, and L. Wang, 2017: Evaluation of CLASS snow simulation over eastern Canada. J. Hydrometeor., 18, 1205-1225, https://doi.org/10.1175/JHM-D-16-0153.1.
Von Salzen, K., and Coauthors, 2013: The Canadian fourth generation atmospheric global climate model (CanAM4). Part I: Representation of physical processes. Atmos.-Ocean, 51, 104125, https://doi.org/10.1080/07055900.2012.755610.

Wang, S., R. F. Grant, D. L. Verseghy, and T. A. Black, 2001: Modelling plant carbon and nitrogen dynamics of a boreal aspen forest in CLASS - The Canadian Land Surface Scheme. Ecol. Modell., 142, 135-154, https://doi.org/10.1016/S03043800(01)00284-8.

Weedon, G. P., G. Balsamo, N. Bellouin, S. Gomes, M. J. Best, and P. Viterbo, 2014: The WFDEI meteorological forcing data set: WATCH forcing data methodology applied to ERA-Interim reanalysis data. Water Resour. Res., 50, 7505-7514, https:// doi.org/10.1002/2014WR015638.

Wen, L., Z. Wu, G. Lu, C. A. Lin, J. Zhang, and Y. Yang, 2007: Analysis and improvement of runoff generation in the land surface scheme CLASS and comparison with field measurements from China. J. Hydrol., 345, 1-15, https://doi.org/ 10.1016/j.jhydrol.2007.06.017.

Whan, K., and F. Zwiers, 2016: Evaluation of extreme rainfall and temperature over North America in CanRCM4 and CRCM5. Climate Dyn., 46, 3821-3843, https://doi.org/10.1007/s00382-015-2807-7.

Whittaker, R. H., and G. E. Likens, 1973: Primary production: The biosphere and man. Hum. Ecol., 1, 357-369, https://doi.org/ 10.1007/BF01536732.

Zhang, Y., S. Wang, A. G. Barr, and T. A. Black, 2008: Impact of snow cover on soil temperature and its simulation in a boreal aspen forest. Cold Reg. Sci. Technol., 52, 355-370, https:// doi.org/10.1016/j.coldregions.2007.07.001.

Zheng, H., Z. L. Yang, P. Lin, J. Wei, W. Y. Wu, L. Li, L. Zhao, and S. Wang, 2019: On the sensitivity of the precipitation partitioning into evapotranspiration and runoff in land surface parameterizations. Water Resour. Res., 55, 95-111, https:// doi.org/10.1029/2017WR022236.

Zhuang, Q., V. E. Romanovsky, and A. D. McGuire, 2001: Incorporation of a permafrost model into a large-scale ecosystem model: Evaluation of temporal and spatial scaling issues in simulating soil thermal dynamics. J. Geophys. Res., 106, 33 649-33 670, https://doi.org/10.1029/2001JD900151. 